\title{
The Glittering Prizes:
}

\section{Career Incentives and Bureaucrat Performance*}

\author{
Marianne Bertrand, Robin Burgess, Arunish Chawla and Guo $\mathrm{Xu}^{\dagger}$
}

April 18, 2019

\begin{abstract}
Bureaucracies are configured differently to private sector and political organizations. Across a wide range of civil services entry is competitive, promotion is constrained by seniority, jobs are for life and retirement occurs at a fixed age. This implies that older entering officers, who are less likely to attain the glittering prize of reaching the top of the bureaucracy before they retire, may be less motivated to exert effort. Using a nationwide stakeholder survey and rich administrative data on elite civil servants in India we provide evidence that: (i) officers who cannot reach the senior-most positions before they retire are perceived to be less effective and are more likely to be suspended and (ii) this effect is weakened by a reform that extends the retirement age. Together these results suggest that the career incentive of reaching the top of a public organization is a powerful determinant of bureaucrat performance.
\end{abstract}

JEL classification: D73, H11, O10

${ }^{*}$ We are grateful to Padamvir Singh, the former Director of Lal Bahadur Shastri National Academy of Administration (LBSNAA), for his help with getting this project started and to LBSNAA and the Indian Planning Commission for collaboration. We thank Blackstone Group and its President Ashref Hashim for help with fielding the surveys of bureaucrat effectiveness. The paper has benefited from comments from Montek Singh Ahluwalia, Nava Ashraf, Oriana Bandiera, James Banks, Timothy Besley, Bronwen Burgess, Michael Callen, Ernesto Dal Bo, Iqbal Dhaliwal, Claudio Ferraz, Fred Finan, Luis Garicano, Robert Gibbons, Alessia Isopi, Aprajit Mahajan, Benjamin Olken, Gerard Padro i Miquel, Rohini Pande, Torsten Persson, Andrea Prat, Padamvir Singh, Adam Szeidl and presentations at American Economic Association Annual Meetings, Berkeley, Bocconi, CEPR Public Economics Conference, CEPR Workshop on Incentives, Management and Organisation, Central European University, Harvard/MIT, Helsinki Centre for Economic Research, HU Berlin, IGC Political Economy Conference, LBSNAA, LSE, Manchester, NBER India Conference, NBER Political Economy Conference, Stanford and Stockholm University. The large-scale data collection effort and data processing which underpins this paper was financed by the University of Chicago and the DFID funded Institutions for Pro-Poor Growth (iiG) Research Consortium and International Growth Centre (IGC). The views expressed here are those of the authors alone and do not necessarily reflect those of DFID. A previous version of this paper has been circulated under the title "The Costs of Bureaucratic Rigidity: Evidence from the Indian Administrative Service".

${ }^{\dagger}$ Marianne Bertrand [University of Chicago Booth School of Business: Marianne.Bertrand@chicagobooth.edu]; Robin Burgess [London School of Economics (LSE): r.burgess@lse.ac.uk]; Arunish Chawla [Indian Administrative Service (IAS): arunish.chawla@gmail.com]; Guo Xu [University of Berkeley, Haas School of Business: guo.xu@berkeley.edu] 


\section{Introduction}

Bureaucrats are a core element of state capacity. They are responsible for implementing policy and may therefore have a critical bearing on societal outcomes. Bureaucrat effectiveness is particularly important in developing economies. Many have recently adopted economic and social reform programs that are aimed at promoting structural change and have the potential to substantially raise living standards. The eventual success or failure of these programs depends centrally on how they are implemented in the field.

Yet, despite their centrality to development and poverty reduction, the incentives civil servants face within bureaucracies are seldom studied. It is striking, for example, how the study of bureaucrats, and professional bureaucracies in general, has lagged well behind that of politicians or private sector managers. While the influence of political leaders on economic growth (Jones and Olken 2005; Besley et al. 2011) and the impact of CEOs on firm performance (Bertrand and Schoar 2003; Bertrand 2009; Kaplan et al. 2012) have been extensively studied, we know very little about what motivates bureaucrats and how this affects development and growth. Political, private sector and civil service leaders all run large organizations and so the career incentives they face may impact organizational performance and a wider set of economic outcomes.

This paper addresses this gap in the literature by studying the elite cadre of civil servants in India - the Indian Administrative Service (IAS). The IAS, known as the "steel frame" of India, is responsible for running all key government departments at the state and federal levels as well as a range of public sector enterprises and corporations. This makes IAS officers a particularly interesting set of bureaucrats to study as they oversee the implementation of policies that have the potential to affect aggregate economic outcomes.

A few key features distinguish professional bureaucratic organizations from other organizations: selection through competitive examinations, a virtual absence of discretionary firing (and hence limited exit), seniority-based progression rules and a fixed retirement age (Bekke et al. 1996; Van der Meer et al. 2015). These rules are a direct response to earlier patronage systems, where appointments, promotions and dismissals were decided based on personal or political favors. ${ }^{1}$ The reliance on objective selection criteria is meant to ensure that the most talented, as opposed to the best connected, are recruited. Once recruited, clear progression rules and limits on discretionary firing are meant to restrict wasteful lobbying or influence activities by agents who seek to affect the principal's decisions (Milgrom 1988,

\footnotetext{
${ }^{1}$ The earliest modern bureaucracies go back to the British Northcote-Trevelyan (1854) report which recommended that recruitment into the civil service be by open examination, that the entry age window be between 19 to 25 years, that entrants should be recruited into a unified, permanent civil service and that promotion should be based on merit, not preferment, patronage, purchase or length of service. Many of the recommendations in the report were influenced by the earlier Macaulay reforms in the Indian Civil Service, the predecessor of the modern IAS which was the first of the British civil services to abolish patronage. The Macaulay Report recommended the replacement of the patronage-based system of appointment in the Indian Civil Service by open and competitive examinations, the establishment of a permanent civil service, and an age window for new entrants of 18-25 years. After recruitment, candidates underwent two years of training - one year of formal training in the UK and one year of district training in India - similar to the training structure of the modern IAS (Fulton 1968; Kirk-Greene, 2000). See also Bai and Jia (2016) for a discussion of the Chinese recruitment system for elite civil servants and its impact on political outcomes.
} 
Prendergast 1999). Seniority-based promotion rules also limit principals' and politicians' ability to engage in favoritism, patronage and corruption by providing objective, impartial criteria for career progression in settings where performance is difficult to measure (Iyer and Mani 2012, Xu 2018). ${ }^{2}$

The IAS shares these classic characteristics of modern professional bureaucracies around the world and this helps to give the findings from our study a wider resonance. Selection into the IAS, as for many other civil services around the world, is based on a competitive entry examination, with the top 100-150 scorers on the exam being admitted each year (out of about 450,000 exam takers). Once selected, IAS officers are allocated to a state, also known as a "cadre", through a rule-based allocation process and officers stay part of the same cadre throughout their career. As is the case in the majority of civil services, promotions within the IAS, as shown in Figure 1, are subject to tenure-based rules, with promotion waves occurring at 4, 9, 13, 16, 25 and 30 years of service. Officers do not move to a higher payscale until the required number of years of experience have been achieved. While the timing of actual promotions closely tracks the promotion grid for junior officers, the discrepancy between minimum and actual tenure required to enter a higher payscale increases for later promotions, which are subject to more stringent performance review and depend on the availability of vacancies.

In the absence of firing and performance pay, career incentives are one of the few ways to motivate bureaucrats. However, a wide entry age window, combined with the tenure-based progression rule and a fixed retirement age of 60 (58 before 1998), implies that some officers who enter the IAS at an older age face a career cap (Figure 2). These older entering officers, because they are less likely to attain the glittering prize of reaching the uppermost echelon of the bureaucracy (which brings significantly higher pay, final salary pensions, prestige and status) before they retire, may therefore be less motivated to exert effort. ${ }^{3}$

This is the core issue we take up in this paper. In particular, we empirically assess whether entering the service older affects IAS officers' on-the-job performance. We also exploit a pension reform that extended the pension age by two years to see whether this helped to motivate previously career-capped officers and improve their performance.

To guide this analysis we develop a simple theoretical model with two types of agents (young/old) and two time periods (junior level/senior level). In each period, agents earn fixed wages and produce output. Output depends on ability and effort. Performance is not directly linked to wages but does affect the ability of the bureaucrat to reach the glittering prize of the senior level. Therefore (i) in the pre-reform period older entrants may be

\footnotetext{
${ }^{2}$ Objective performance measures are also confronted with the multi-tasking problem where bureaucrats exert effort only on measurable dimensions (Holmstrom and Milgrom 1991; Baker et al. 1994). Rasul and Rogger (2017), for example, show that the introduction of monitoring can result in excessive "box ticking" activities that are detrimental to project completion rates.

${ }^{3}$ In the IAS and across a whole range of civil services around the world competition is most intense for the uppermost echelon jobs and the returns to securing these positions significant. Since pensions are directly tied to final salaries in the IAS, as is often the case for civil servants across the world, reaching the top payscale is particularly valuable not just because it carries a significant pay increase but also because that pay increase gets baked into a final salary pension which can be enjoyed for many years post-retirement. Appendix Table A1 shows that the salary gain from reaching the top (Chief Secretary) vs. the penultimate (Principal Secretary) payscale is a highly significant $25 \%$ on average (and up to $60 \%$ ).
} 
disincentivized because they have to retire before they reach the senior level and (ii) the pension reform will diminish this differential in incentives between young and old entrants.

To look at these effects we must first confront the key empirical barrier associated with studying civil servants - the lack of reliable individual performance measures (Oyer and Schaefer 2010). Politicians need to win elections and the performance of CEOs may be reflected in sales or stock prices. What the "output" of civil servants is, is much less clear particularly for generalists like IAS officers who work in a variety of departments across their career. ${ }^{4}$ We get around this difficulty by introducing a new approach to measure bureaucrat performance. We poll a large group of stakeholders who operate in the same state as an IAS officer to get 360 degree feedback on their perception of the performance of that named civil servant. ${ }^{5}$ The key stakeholders we survey include IAS officers, state civil servants, elected politicians, representatives of business associations, local TV and print media, and civil society organisations. For each IAS officer they know, we ask stakeholders to grade them on a 1 (low) to 5 (high) scale for: effectiveness, probity, the ability to withstand illegitimate political pressures, pro-poor orientation and overall rating. We gather this information in the 14 main states of India and cover the majority of centrally recruited IAS officers.

Figure 3, which is based on these surveys, motivates much of our subsequent analysis. The figure shows the raw relationship between an IAS officer's perceived effectiveness in the stakeholder survey and the officer's age at the time of entry into the IAS. ${ }^{6}$ As expected if a lack of promotion prospects is particularly demotivating for officers that enter the service older, we find a negative relationship between officers' perceived effectiveness and their age at entry into the IAS. This decline coincides with the discontinuous decline in the probability of reaching the top payscale, as shown in Figure 2.

Exploiting the non-linear variation in the probability of reaching the top payscale, we find that officers who are constrained from reaching the senior-most positions perform worse. Compared to unconstrained officers, career-capped officers are perceived to be less effective, less likely to withstand illegitimate political pressure, less likely to be pro-poor and are deemed to perform worse overall.

We leverage several empirical strategies to establish that the results are not driven by differences between younger and older entrants. To ensure that the negative association is indeed driven by bureaucrats being unable to attain the glittering prize of reaching the top payscale, we make use of a natural experiment. The 1998 pension reform increased the retirement age for IAS officers by two years from 58 to 60 . From a career perspective, the reform disproportionately benefited career-capped entrants as these officers became more likely to qualify for senior positions. This allows us to use a difference-in-differences design to compare older and younger entrants before and after the reform. While older entrants who entered prior to the reform performed worse, the relaxation of the disincentive coincides with the disappearance of the negative performance gap for cohorts entering after the reform.

\footnotetext{
${ }^{4}$ In our data the average posting length of an IAS officer is 16 months and officers careers typically involve postings in a large variety of departments.

${ }^{5}$ The term "360 degree" feedback refers to multi-source feedback used by organizations to elicit information about employees' work-related performance.

${ }^{6}$ Appendix Figure B2 reproduces the same figures for the remaining 360 performance measures.
} 
Consistent with incentives, the reform effects are concentrated among the marginal entry age groups for which the reform lifted the career-cap.

We then extend the results from the 360 cross-section to a panel setting, making use of suspensions as a direct measure of performance to hold constant selection. The panel allows us to hold constant self-selection by limiting the analysis to cohorts that joined pre-reform. We validate our subjective performance measures by showing that career-capped officers are more likely to be suspended. Mirroring previous result, we also find that this differential suspension probability only appears in the pre-reform period and vanishes after the career progression constraint is relaxed.

In a final test, we exploit the quasi-random allocation of officers to states which implies that, holding an officer's age at entry and the size of his or her cohort constant, there will be as good as random variation in the share of officers in the batch that are younger or older than the given officer. We find that officers that enter the state cadre with more younger officers are deemed to be less effective and less able to withstand illegitimate political pressure but that these effects are mitigated by the 1998 pension reform. This lines up with our previous results and has the advantage that we can hold age at entry constant and just rely on the comparison of relative age among officers in the same cohort to identify the impact of career incentives on bureaucrat performance.

Taken together, we find compelling evidence that the career incentives bureaucrats face influence their effectiveness. Our paper thus shines a light on the costs associated with rigid progression rules in organizations (Ke et al. 2016). Given that a large number of professional civil services around the world are organized like the IAS, understanding these costs and gaining insights into how bureaucrats might be better motivated represents an important undertaking. Indeed, it is central to improving the implementation of public policy, to promoting economic performance and to improving societal outcomes. As such, the results resonate with the literature on firm performance, where the practice of fasttracking high performers is often considered to be "good" management practice (Bloom et al. 2013; Bloom et al. 2016).

The remainder of the paper is organized as follows. Section 2 provides details about the institutional background and introduces our data sources. Section 3 contains our main results on the links between career incentives and bureaucrat performance. Section 4 concludes.

\section{Background and Data}

\subsection{The Indian Administrative Service}

The Indian Administrative Service (IAS), the successor of the colonial Indian Civil Service (ICS), is the elite administrative civil service of the Government of India. The ICS was one of the earliest professional civil services to enshrine the principles of meritocratic age based entry, rule based promotion, life-long careers and fixed retirement (Kirk-Greene 2000). These principles influenced the development of modern civil services not just in India and 
other UK Commonwealth countries but across a wide range of developed and developing countries (Northcote and Trevelyan 1854; Weber 1922). For this reason the organization of the IAS bears a striking resemblance to a whole range of civil services across the world. ${ }^{7}$ Indeed, faced with the difficulty of measuring the performance of public servants, a whole range of public organizations beyond civil services have developed organizational features that resemble those of the IAS.

In 2014, the IAS had an overall strength of around 3,600 centrally recruited officers. These officers are civil service leaders, occupying key positions critical for policy implementation. The most senior civil service positions - the Cabinet Secretary of India, the Chief Secretary of States, heads of all state and federal government departments - are all occupied by IAS officers. Senior IAS officers also oversee major state-owned enterprises and state-run corporations. Senior IAS officers are known and publicly visible.

The recruitment of officers is based on performance in the Civil Service Exam, which is organized annually by the Union Public Service Commission (UPSC). Entry into the IAS is extremely competitive, with several hundred thousand applicants competing for a small number of spots. In 2015, for example, 465,882 UPSC exam takers applied for only 120 IAS slots. The highest performing exam takers are typically offered slots in the IAS.

To be eligible for the IAS, candidates must be aged between 21 and 30 in the year of the competitive exam. ${ }^{8}$ This constraint is relaxed for reserved groups, who can enter up to 35 years of age. Once selected, IAS officers are allocated to a state cadre in the subsequent year. The assignment to a state is typically fixed for life, ${ }^{9}$ and officers are attached to their state cadre even when serving in Delhi or abroad. After selection and allocation to the state cadre, IAS officers undergo training at the Lal Bahadur Shastri National Academy of Administration (LBSNAA) and in the states they have been assigned to. The two-year training consists of one year of academic training at the LBSNAA ("course work") and one year of practical training ("district training"). After training, recruits are initially placed in the district administration (e.g. as district collectors), and are subsequently promoted to higher level positions. Promotion is seniority-based occuring after 4, 9, 13, 16, 25 and 30 years and all officers have to achieve these years of service to be eligible for the next payscale. The discrepancy between the minimum and actual tenure required to enter a higher payscale increases for later promotions (Figure 1), which are subject to more stringent performance review and depend on the availability of vacancies (see Appendix Table A1). Finally, retirement occurs at 60 years of age for both male and female officers (58 years before 1998) and pensions enjoyed are linked to the final payscale attained. Figure

\footnotetext{
${ }^{7}$ The Westminster system of an independent and life-long civil service with merit-based selection was adopted across most of the former British Empire colonies. Seniority-based promotion and fixed retirement age were both features meant to shield civil servants from political interference and ensure independence. Civil services in former territories of British India like Pakistan, Myanmar and Bangladesh are thus organized in nearly the exact same way as the modern Indian Administrative Service. More generally, however, these "career-based" civil service systems - characterized by competitive entry, seniority-based promotion, life-long service and fixed retirement ages - are considered classic features of bureaucracies which are shared by civil services around the world (Bekke et al. 1996; Van der Meer et al. 2015).

${ }^{8}$ The cut-off date is 1 August in the year of the exam. Admitted officers enter in the next year.

${ }^{9}$ The only exception which allows for transfers across states is in the case of marriage to another IAS officer. These cases, however, have to be approved on a case-by-case basis and are rare.
} 
4 shows the distribution of age at exit for the set of retired IAS officers. There is very little exit before the designated retirement age - $20 \%$ of all officers exit before 58 years of age, and only $8 \%$ of officers exit with fewer than 50 years of age.

A wide entry age window, combined with seniority-based progression and a fixed retirement age implies that those who enter older will face barriers to attaining the glittering prize of reaching the senior payscales. This may disincentivize effort and lower the effectiveness of career-capped officers, as attaining the senior payscales brings significant benefits. Moving from the penultimate payscale to the highest payscale is associated with a salary gain of between 25-60\% (Appendix Table A1) and the pensions which officers enjoy are directly tied to the last payscale attained. ${ }^{10}$ Therefore attaining the highest payscale even in the last year of service will bring significant long-term benefits. These pecuniary benefits are amplified by the professional and social prestige that comes from reaching the top tier of the Indian Administrative Service and, as with final salary pensions, these non-pecuniary benefits can be enjoyed post-retirement.

The potential cost of this bureaucratic rigidity, indeed, has been acknowledged by both the Government of India and the media. The 10th Report of the Administrative Reform Commission, for example, points out that a higher age at entry mechanically implies a "shorter service span, which means [old entrants] may not have adequate opportunities to contribute to policy-making at higher levels". ${ }^{11}$ Similarly, media reports frequently point to the disadvantages of combining seniority-based promotion with a fixed retirement age, suggesting that "seniority is an objective basis for promotion but often an ineffective one" 12 and "the problem goes down to the age of entry, since [...] promotions go as much by seniority as merit alone." ${ }^{13}$ In line with the recommendations of the Administrative Reform Commission, these media articles call for more flexibility, concluding that the service must "put the best people, irrespective of age, in the right positions", and that "from [an] agebased [retirement] system, we should move to fixed tenures [...] for all irrespective of joining age". ${ }^{14}$ However, despite repeated calls by these Commissions and other bodies to lower the maximum age at which officers can enter the service, ${ }^{15}$ the actual window has been widening over time. ${ }^{16}$

\footnotetext{
${ }^{10}$ See 18(1) of the All India Services (Death-Cum-Retirement Benefits) Rules of 1958. Senior IAS officers also enjoy substantial perks, such as subsidized housing, driver and other amenities. Retired officers who occupied senior positions often pursue lucrative advisory roles, acting as board members for both private and public companies.

${ }^{11}$ Administrative Reform Comission (ARC, 2008), Chapter 5, page 96.

${ }^{12}$ The Indian Express (1 April 2015), "A new kind of babu", by Manish Sabharwal.

${ }^{13}$ The First Post India (22 December 2012), "Quotas: How bias in favour of SC/STs works against them", by R. Jagannathan.

${ }^{14}$ The Hindu (8 September 2012), "Fixed tenure a way forward on promotions", by Vivek Katju.

${ }^{15}$ See Administrative Reform Commission (2008), p.105.

${ }^{16}$ The age at entry window for the Indian Civil Service (ICS), the precursor of the IAS, was fixed between 21 and 24 years of age before independence and geared towards fresh British graduates from Oxford and Cambridge. After independence this narrow window was maintained into the early 1970s. However, mounting political pressure to include poor and disadvantaged candidates and those from non-elite academic institutions (who it was argued need more preparation time) has pushed the entry window steadily outwards and away from the 19-25 window recommended by Northcote-Trevelyan (1854). The pressure to extend age at entry continues today - the age limit was extended to 32 years for general candidates and 37 years for reserved groups in 2014 .
} 


\subsection{Measuring bureaucrat performance}

We designed and implemented a large-scale survey to collect cross-sectional data on the subjective assessments of IAS officers in the 14 main states of India ${ }^{17}$ for 2012-13 which unlocked our ability to study the relationship between career incentives and bureaucrat performance. These 14 states comprise the major states of India, covering $84 \%$ of India's population (Census 2011). IAS officers were assessed on five dimensions: (i) effectiveness on the job, (ii) probity, (iii) ability to withstand illegitimate political pressure, (iv) pro-poor orientation, and (v) overall rating. ${ }^{18}$ All dimensions are scored on a 5 point integer scale, where 1 is the lowest and 5 the highest performance.

To obtain assessments from a wide range of stakeholders, we elicited these subjective assessments from respondents of six societal groups in each state: (i) a random sample of IAS officers, (ii) a random sample of state civil servants, (iii) politicians, drawn from a random sample of members of the legislative assembly (MLA), (iv) industry, business and professional associations, comprised of the highest representatives for the major associations, (v) print and TV media, comprised of key journalists covering politics for the largest newspapers and TV stations by circulation and viewership respectively, and finally (vi) civil society, comprised of the highest representatives of major NGOs, trade unions and think-tanks. For each state, we sampled about 10 respondents from each of the groups. ${ }^{19}$

We compiled a list of all centrally recruited IAS officers for each state. In each state, interviewers then systematically worked through the list, asking respondents to provide assessments for each known candidate. We excluded junior officers with less than 8 years' tenure as they are often in district postings and less visible. Finally, we recorded the source of information to account for reporting biases, differentiating between information obtained through personal exposure, friends or social networks, or the media.

Table 1 provides summary statistics of the 360 degree measures. The sample sizes range from $N=15,153$ for the probity measure to $N=17,753$ for the effectiveness measure. The number of complete assessments across all dimensions is $N=14,037$. We were able to elicit scores for about $70 \%$ of all IAS officers in the sampling frame. ${ }^{20}$ All dimensions are correlated, with the highest correlation being between pro-poor orientation and the ability

\footnotetext{
${ }^{17}$ These states are: Andhra Pradesh, Bihar, Gujarat, Haryana, Karnataka, Kerala, Madhya Pradesh, Maharashtra, Orissa, Punjab, Rajasthan, Tamil Nadu, Uttar Pradesh and West Bengal. We excluded joint cadres (Union Territories, Assam - Meghalaya, Manipur - Tripura), as well as the smaller states (Jammu \& Kashmir, Nagaland) and the new cadres resulting from state splits in 2000 (Jharkhand, Uttarakhand, Chhattisgarh) from the sample.

${ }^{18}$ The exact questions are: (i) "How would you rate his/her effectiveness in his/her assignment?" (ii) "How much do you feel this officer uses his/her official position for making money?" (iii) "How much do you feel this officer can withstand illegitimate political pressure?" (iv) "How sensitive is this officer to the needs of the poor and weaker sections in society?" (v) "What is your overall rating of this officer?". To ensure that higher values indicate greater performance across all five indicators, we invert the corruption question (ii) and refer to it as "probity" throughout the paper.

${ }^{19}$ For logistical reasons, we were unable to survey state civil servants in Gujarat and IAS officers in Punjab.

${ }^{20}$ While we find some evidence for differences in individual traits between officers with 360 scores and those without, the differences remain stable around the pension reform (Appendix Table A2). Reweighting the sample using inverse probability weighting leaves the estimates nearly unchanged. In addition, we address concerns of sample selection by validating our results using administrative outcome data available for all IAS officers (Section 3.4).
} 
to withstand illegitimate political pressure.

A known concern regarding subjective measures is whether these capture actual information or merely biased perceptions (Baker et al. 1994; Prendergast and Topel 1996). Respondents, when providing assessments, may compress ratings around norms or systematically provide positive or negative ratings to all assessed officers ("centrality bias"). In the presence of halo effects, a respondent's overall impression of an officer may also affect the assessments on each of the performance dimensions. Respondents may also base their assessment on public information, such as media reporting, generating an "echo chamber."

We address concerns of reporting biases in three ways. First, we purge respondentspecific biases in measurement. Accounting for level differences in reported effectiveness is important: IAS officers, for example, tend to rate their colleagues more highly, while media representatives provide, on average, more negative ratings (Appendix Table A3). Second, we control for source of information fixed effects to alleviate "echo chamber" biases, namely that those who did not know IAS officers personally merely repeat (potentially biased) perceptions originating in the media. For example, IAS officers known personally by a respondent tend to receive higher effectiveness rating than those rated based on knowledge through media or social networks (Appendix Table A4). Third, we account for interviewer fixed effects to ensure our results are not driven by artifacts of the data collection method. Finally, in Section 3.4, we also provide evidence on actual suspensions, a relatively clear-cut objective measure of (non-)performance, to complement the subjective measures.

Before concluding the discussion of our measurement framework, it is worthwhile to reflect on what the subjective measures capture. As subjective measures, our cross-sectional 360 measures will not only capture contemporaneous performance of officers but also their past performance. As survey respondents are likely to gradually update their beliefs about the performance of individuals (Frederiksen et al. 2017), these elicited measures will tend to be highly persistent. As Appendix Table A5 indeed shows, our performance measures are correlated both with contemporaneous as well as past suspensions, a direct measure of (non-)performance. The cumulative nature of the 360 scores will be important when studying the pension reform in Section 3.3.

\subsection{Administrative data}

To study the determinants of effectiveness, we combine our 360 degree survey data with administrative data obtained from the LBSNAA, the academy where IAS recruits undergo training before their first posting. We use three sources of administrative data. First, we draw upon the descriptive rolls of 5,635 IAS officers who entered between 1975-2005. This dataset contains a rich set of individual background characteristics ranging from year and location of birth to caste, family background, and educational degrees and work experience, allowing us to examine how pre-determined characteristics at point of entry into IAS correlate with later effectiveness.

Second, we use data on internal rankings which covers 4,107 IAS officers from 1972-2009. This dataset provides information about the initial allocation of officers to cadres, the size of 
their cohorts in a given entry year, their scores on the entry exam as well as their marks on the training courses. Finally, on-the-job outcome measures are derived from the executive record sheets of 10,817 IAS officers who entered between 1949-2014. These record sheets contain detailed information about the postings (e.g. job title, department and duration) and payscales of each officer throughout his or her career. This dataset allows us to track suspension episodes for each officer. The data is provided by the Ministry of Personnel, Grievances and Pensions and is publicly available.

Table 2 summarizes the IAS officers' background characteristics for the cross-section of 2012-13, providing a snapshot of the IAS at the time of our survey. The typical IAS officer is about 25.5 years old at the time of entry into the IAS. A large majority of IAS officers are male (86 percent). More than a quarter of IAS officers are drawn from minority castes $(\mathrm{OBC}=8$ percent; $\mathrm{SC}=14$ percent; $\mathrm{ST}=5$ percent $)$.

\section{Career Incentives and Bureaucrat Performance}

\subsection{Conceptual framework}

We introduce a simple conceptual framework to guide our empirical analysis. We consider two types of bureaucrats: old entrants (indexed $a=1$ ) and young entrants $(a=0)$. The two types of bureaucrats can differ in their ability levels $\mu_{a}$. Once recruited, a bureaucrat's career is divided in two periods, junior-level (indexed $t=1$ ) and senior-level $(t=2$ ). Bureaucrats receive a fixed wage $w_{t}$, which differs across levels of seniority. Bureaucrats can exert effort $e_{a t}$ to produce output at a convex cost of $C\left(e_{a t}\right)=\frac{c}{2} e_{a t}^{2}$. The production function for bureaucrat output depends on both effort and ability: $y_{t}\left(e_{a t}, a\right)=e_{a t}+\mu_{a}$.

Bureaucrats choose effort $e_{a t}$ to maximize their payoff over their career:

$$
\max _{e_{a 1}, e_{a 2}} V=w_{1}-\frac{c}{2} e_{a 1}^{2}+\Pi\left(y_{1}\left(e_{a 1}, a\right), a\right)\left(w_{2}-\frac{c}{2} e_{a 2}^{2}\right)
$$

where $\Pi\left(y_{t}\left(e_{a t}, a\right), a\right) \in[0,1]$ is the promotion function, capturing the probability that a bureaucrat of type $a$ and output level $y_{t}\left(e_{a t}, a\right)$ is promoted to the senior level. We assume that the probability of promotion is linear in production conditional on bureaucrat type $a$ : $\Pi\left(y_{t}\left(e_{a t}, a\right), a\right)=\pi(a) y_{t}\left(e_{a t}, a\right)$ The probability of promotion thus increases with performance. ${ }^{21}$ This reflects the implicit incentives observed in many public organizations: performance is not directly linked to wages $w_{t}$ but affects the prospects of the bureaucrat to reach the senior-level payscales - the "glittering prize." Without loss of generality, we assume that a bureaucrat who is not promoted exits, thus earning a wage of zero. ${ }^{22}$

In the presence of time-based promotion caps, older entrants may not only differ by type but also in the extent to which they can feasibly reach the senior-most position. In the context of the IAS, entrants aged 28 or above are capped out from reaching the top payscale - these old entrants will have to retire by the time they have served the minimum amount of time to qualify for the senior-most promotion. This career cap can be modelled

\footnotetext{
${ }^{21}$ We assume $w_{2} / c+\mu_{a} \leq 1$ so that the promotion probability is well defined.

${ }^{22}$ Alternatively, $w_{2}$ can be interpreted as the wage difference between being promoted vs. staying in office.
} 
as $\pi^{\text {Pre }}(1)=0$ for those who are career-capped pre-reform. Given the inability to fast-track high performers for the promotion to the senior level, these old entrants will have no chance to make it irrespective of their performance. In contrast, greater performance will translate into higher promotion prospects for the young entrants $1 \geq \pi^{P r e}(0)>0$.

Proposition 1 Let $e_{\text {at }}^{*}$ denote the bureaucrat's optimal effort choice. Pre-reform performance differences between old versus young entrants at the junior level will capture a combination of incentive and selection effects:

$$
\Delta y_{1}^{\text {Pre }} \equiv y_{1}\left(e_{11}^{*}, 1\right)-y_{1}\left(e_{01}^{*}, 0\right)=-\frac{w_{2}}{c} \pi(0)^{\text {Pre }}+\left(\mu_{1}^{\text {Pre }}-\mu_{0}^{\text {Pre }}\right)
$$

The above result follows from the model's first order condition and backward induction. The proof is provided in the Appendix C3.

Compared to older entrants, younger entrants will unambiguously exert more effort due to their ability of reaching the top. The first term on the right hand side of equation (2) thus captures the incentive effect of the "glittering prize." The strength of the incentive effect is increasing in the post-promotion wage and the probability of promotion. In addition, differences in performance may also be driven by ability differences $\left(\mu_{1}^{\text {Pre }}-\mu_{0}^{\text {Pre }}\right)$ - a selection effect. In our first empirical test (Section 3.2), we estimate the empirical counterpart to Proposition 1 by comparing the performance between older and younger entrants. We aim to isolate career incentives by controlling for a rich set of individual characteristics.

The pension reform of 1998 provides empirical variation in $\pi(a)$, which we exploit in our second empirical test (Section 3.3). More specifically, the extension of the retirement age by 2 years enables a subset of previously career-capped officers to reach the top, so that $1 \geq \pi^{\text {Post }}(1)>0 .^{23}$ Since the decision to exert effort depends on whether effort translates into greater promotion prospects, the elongation of the career will induce an incentive effect for the old entrants. Hence, this policy variation allows us to isolate the incentive effect under less restrictive assumptions. The following proposition shows this result:

Proposition 2 The comparison in performance between older and younger entrants before and after the pension reform will capture:

$$
\Delta y_{1}^{\text {Post }}-\Delta y_{1}^{\text {Pre }}=\frac{w_{2}}{c} \pi(1)^{\text {Post }}+\left(\Delta \mu^{\text {Post }}-\Delta \mu^{\text {Pre }}\right)
$$

where $\Delta \mu^{\text {Post }}=\mu_{1}^{\text {Post }}-\mu_{0}^{\text {Post }}$ denotes the ability difference between old and young entrants post-reform and $\Delta \mu_{1}^{\text {Pre }}=\mu_{1}^{\text {Pre }}-\mu_{0}^{\text {Pre }}$ denotes the difference pre-reform. The above result follows from differencing equation (2) around the reform. A proof is provided in the Appendix C3.

If the pension reform does not change the ability difference between older and younger entrants, the selection effect $\left(\Delta \mu^{\text {Post }}-\Delta \mu^{\text {Pre }}\right)$ is differenced out. The observed change

\footnotetext{
${ }^{23}$ We assume that the promotion prospects for the young entrants remain constant before and after the reform $\left(\pi^{\text {Pre }}(0)=\pi^{\text {Post }}(0)\right)$.
} 
in performance between older versus younger entrants post-reform would only reflect the incentive effect of being able to reach the top. In the second test (Section 3.3), we estimate the empirical counterpart to Proposition 2 by comparing the performance gap between older and younger entrants before and after the pension reform. We also provide evidence that the observable differences between older and younger cohorts remain statistically constant over time, allowing us to isolate the incentive effect under less restrictive assumptions. In the third test, we will also corroborate our main results with within-officer panel evidence that fully holds constant selection (Section 3.4).

Proposition 2 also gives rise to a heterogeneity test. Among old entrants, those who see the largest gain in the probability of reaching the top $\left(\pi(1)^{\text {Post }}\right)$ from the pension reform are likely to exhibit the greatest effort. In Section 3.3, we exploit variation in the extent to which the pension reform removes the career cap on reaching the top by exploiting the fact that older entrants can be divided into two sub-populations: those who were career capped pre-reform but now qualify for the senior-most position post-reform (the "marginal age group"), and those who are inframarginal and still have to retire before being eligible for the top position post-reform (the "too old" group).

Generality of the framework. The simple model also highlights two key institutional features on which the performance effects depend. First, the most important institutional parameter is the "prize" for reaching the top, as captured by $w_{2}$. More generally, this "prize" can reflect both pecuniary (such as salary and pensions) and non-pecuniary gains (such as status). In the context of the IAS, the average gain from reaching the ultimate vis-a-vis the penultimate payscale corresponds to a gain of $25 \%$ on average (and up to $60 \%$ ) and these gains persist post-retirement in the form of final salary pensions. ${ }^{24}$ In most hierarchical organizations, these salary gains are also likely to be positively correlated with a host of non-pecuniary gains: span-of-control and power, for example, increase with salaries and are defining features of higher status. As with pecuniary benefits, non-pecuniary benefits like status are likely to extend beyond retirement.

Second, how strong the incentives of reaching the top are depends on the degree of merit-based promotions at the top of the organization $\pi(a)$. In absence of a merit-based competition at the top, there would be no incentive response as the returns to effort would be muted. In the Indian context, junior-level promotions are almost perfectly time-based, whereas senior-level promotions are subject to more stringent performance review and depend on the availability of vacancies (Figure 1). Both features are not specific to the context of the Indian Administrative but hold in many bureaucratic organizations. Indeed, given the British root of the IAS and a global move towards permanent, professional bureaucracies we find that the bulk of civil services around the world are organized in a similar fashion (Bekke et al. 1996; Van der Meer et al. 2015).

\footnotetext{
${ }^{24}$ The basic pay range in 2012 for the penultimate payscale is Rs. 49,400-79,000, depending on the duration spent within the payscale. The average pay within the penultimate payscale is Rs. 64,200 (see Appendix Table A1 - IAS Promotion Guidelines).
} 


\subsection{Test 1: Age at entry and individual performance}

In presence of promotion rigidities, we hypothesize a negative association between age at entry and the effectiveness of IAS officers. Compared to individuals who enter younger, those entering older and less likely to reach the top may be less motivated to perform. Guided by Propositon 1 (Section 3.1), we implement the following empirical model to estimate the relationship between age at entry and the subjective performance scores:

$$
y_{i j}=\alpha \times a g e \_e n t r y_{i}+\mathbf{x}_{\mathbf{i}}^{\prime} \beta+\theta_{j}+\varepsilon_{i j}
$$

where $y_{i j}$ is the subjective rating of officer $i$ given by respondent $j$. The key explanatory variable age_entry $y_{i}$ denotes the officer's entry age. The vector $\mathbf{x}_{\mathbf{i}}$ contains officer-specific background characteristics. To hold constant observable officer-specific differences, we use a rich set of background characteristics. These include individual socio-economic background characteristics, education, work experience and entry exam and training scores as described in more detail in Table 2. The coefficients $\theta_{j}$ are respondent fixed effects. These fixed effects confine the comparison among officers rated by the same individual, thus removing respondent-specific differences in scoring. As no respondent rates officers in more than one state, these respondent fixed effects also control for any state-specific differences in ratings. Finally, we include state $\times$ intake year fixed effects (e.g. entry cohort of Gujarat-1990) to confine the comparison to officers who entered in the same year and were allocated to the same state. In a cross-section, this is equivalent to absorbing state and tenure specific profiles in ratings. $\varepsilon_{i j}$ is the error term, which is clustered at the officer level $i$.

The results are summarized in Table 3. All columns estimate the same regression described in equation (4), except that we vary the dependent variable of interest to span all of the five subjective performance measures considered in our 360 degree survey. To streamline the exposition, we first report the results for the sample of officers who entered before the 1998 pension reform and then present the full sample results in Table 4. Confirming the visual evidence in Figure 3, there is a negative and statistically significant relationship between age at entry and perceived effectiveness when comparing among assessments provided by the same respondent (Panel A, Column 1). The relationship is quantitatively similar when comparing only within the officer's cohort (Column 2) and controlling for the battery of individual characteristics (Column 3).

The results are comparable for the remaining 360 scores. Older entrants are perceived as less able to withstand illegitimate political pressure (Panel B, Column 3), and are perceived to perform lower overall (Column 5). While there is no significantly negative association between age at entry, probity and pro-poor orientedness, the coefficient is negative suggesting that - if anything - older entrants are perceived as more corrupt and less pro-poor (Columns 2 and 4 ). The estimated elasticities are also economically relevant. For effectiveness, the impact of moving age at entry from 22 to 30 implies a $3 \%$ decline in perceived effectiveness relative to the mean of the dependent variable. This corresponds to a decline in the perceived effectiveness rating by around 0.1 standard deviations. When benchmarked against

entry exam scores, the increase in age at entry by an additional year corresponds to a de- 
crease in entry exam scores by 0.28 standard deviations. ${ }^{25}$ The magnitudes are comparable for the remaining 360 measures.

Of course, despite the battery of controls in Table 3, we cannot rule out other explanations beyond career incentives that might explain a negative correlation between age at entry and bureaucratic performance. In particular, with the empirical test conducted in Table 3, we cannot conclusively separate the incentive effect from the selection effect (Proposition 1). We can however partially address concerns of unobserved correlates. We do this in several ways. First, we verify the robustness of our results to sample restrictions, such as confining the sample to only officers aged 30 or below or excluding female officers, for whom fertility decisions might interact with entry age. We also conduct a bounding exercise following Altonji et al. (2005). With the standard assumptions and implementation of Oster (2017), we find that the amount of selection on unobservables would need to be between at least 2-3 times larger relative to selection on observables to "explain away" our observed negative association (Appendix Section C2). Finally, we propose in the following sections alternative empirical tests that make more direct use of the variation in the extent to which the promotion rigidity limits career progression by leveraging the variation induced by the pension age reform.

However, before proceeding to these alternative tests, we note that the patterns in Figure 2 suggests that, if it is indeed career incentives that drive the relationship between age at entry and bureaucratic performance, the relationship might not be the linear one currently estimated. In particular, based on the evidence in Figure 2, very young IAS officers (aged 22-23 at entry) have virtually the same high probability of reaching the top while very old IAS officers (aged 28-30 at entry) have nearly the same low probability of reaching the top. There is a large drop in the probability of reaching the top going from aged 24 at entry to 27 . This observed non-linear relationship between the probability of reaching the top and age at entry suggests a refinement of the analysis of Table 3 where we can assign to each officer, based on his or her age at entry, a probability of reaching the top of the bureaucracy. This refinement is useful in that there is no a priori reason to expect that alternative explanations for a relationship between age at entry and bureaucratic performance would follow the specific non-linear mapping between age at entry and probability of reaching the top of the bureaucracy. Moreover, by focusing on the probability of reaching the top by age at entry, we can also linearly control for age at entry and hence directly account for alternative explanations that may drive a more linear negative correlation between age at entry and performance. This is what we do in Columns 4 and 5 of Table 3, Panel A. The variable "reaching top," is computed as the share of all retired officers by 2012-13 with the same age at entry who reached the highest payscale, the Chief Secretary level. ${ }^{26}$ This is the payscale for which officers only become eligible after serving at least 30 years. Consistent with the bureaucratic rigidity explanation, and with the demotivating effect for older officers of having a lower likelihood of attaining the glittering prize of attaining the

\footnotetext{
${ }^{25}$ Appendix Table A7 reports the full set of coefficients.

${ }^{26}$ See Appendix Table A8 for the exact shares computed by bin. These are also shown visually in Figure 2 (pooled) and and broken out by pre and post-reform cohorts in Figure 5.
} 
Chief Secretary level, we observe a strong positive correlation between "reaching top" and bureaucratic performance.

\subsection{Test 2: Age at entry, pension reform and individual performance}

To provide more direct evidence that being more likely to reach the upper echelons of the bureaucracy improves performance, we exploit a pension reform in 1998. While the pension age had been kept at 58 for nearly 40 years, ${ }^{27}$ this reform extended the retirement age to 60 for all serving officers (Figure 4). Figure 5 shows the probability of reaching the top by age at entry broken down by those who retired before and those who retired after the pension reform. The figure shows a clear "outward" shift in the probability of reaching the top across all age at entry bins. If the positive relationship between individual effectiveness and the probability of reaching the top payscale indeed captures differential incentives induced by the progression cap, we expect the performance gap between older and younger entrants to be smaller after the reform. In line with Proposition 2 (Section 3.1), this elongation of an officer's working life could enhance their career incentives (and hence performance), particularly for those who had been constrained in reaching the uppermost echelons of the bureaucracy. By making this glittering prize more attainable the reform should close the gap in performance between older and younger entrants.

In practice, we implement this test by augmenting equation (4) with an interaction term between age at entry and a dummy that is 1 if the officer entered the IAS after the pension reform in 1998, 0 otherwise:

$$
y_{i j}=\alpha \times a g e \_ \text {entr } y_{i}+\beta \times \text { age_entry } y_{i} \times \text { Post98_Cohort }{ }_{i}+\mathbf{x}_{\mathbf{i}}{ }^{\prime} \delta+\theta_{j}+\varepsilon_{i j}
$$

where Post98_Cohort $i$ is the reform dummy that is 1 for cohorts who entered in 1998 and after. The other variables remain as described in equation (4). We include the same set of individual background controls and the same respondent fixed effects $\theta_{j}$. Departing from the original equation (4), however, the augmented specification allows the impact of age at entry to vary by whether the officer entered in a cohort before or after the 1998 pension reform. As before, the standard errors are clustered at the indvidual officer level.

A change in the performance gap could reflect two separate mechanisms (Proposition 2). First, it is possible that older age entrants will exert more effort on the job when faced with a longer expected tenure post-reform. Second, it is possible that the self-selection of older age entrants will change post-reform. Given the cross-sectional nature of the 360 performance data, we cannot fully separate these two mechanisms. We can only ask whether the impact of age at entry is weaker among officers that joined the IAS after 1998 compared to the officers that joined prior to 1998. The results are reported in Table 4. We first report the estimates separately for the pre- and post-reform cohorts. Consistent with the hypothesis that the pension reform improved the relative performance of older-at-entry IAS officers by relaxing the constraint in career progression, the results show that the negative performance

\footnotetext{
${ }^{27}$ The last pension reform before 1998 was in 1962, when the retirement age was raised from 55 to 58.
} 
gap between an older and younger entrant is driven by the pre-reform period. While IAS officers who entered a year older are deemed, on average, to perform 0.013 points lower pre-reform (Panel A, Column 1), the negative relationship reverts for post-reform cohorts (Column 2). The reversal of the gap is confirmed in the full sample, where the impact of age at entry is allowed to vary by pre- and post-reform cohorts (Column 3).

To alleviate the concern that officers who entered after the reform will also be mechanically less experienced and that there might be a systematic relationship between tenure and performance by age at entry, Column 4 allows the impact of age at entry to linearly vary with number of years of experience by including the interaction age_entry $y_{i} \times$ intake_year $r_{i}$. This ensures that our results are not driven by trends that differentially affect older entrants. This additional control increases the size of the estimated coefficient on the variable of interest (interaction of age at entry with post 98 cohorts). Finally, Column 5 interacts all individual background controls with the reform dummy. The post-reform reversal in the performance gap between older and younger entrants remains robust, and the interactions between the individual characteristics and the reform remain jointly insignificant.

Panel B of Table 4 shows that we obtain qualitatively similar results throughout the five subjective performance measures: while younger officers who entered pre-reform are seen as less corrupt, more able to withstand illegitimate political pressure, more pro-poor and deemed to perform higher overall, this positive performance gap vanishes among officers who joined after the pension reform. Finally, Figure 7 provides visual evidence by plotting the impact of the propensity to reach the top on effectiveness by year. Given the small number of observations in this cross-section, the years are binned to increase the precision of the estimates. While there is a negative performance gap between older and younger entrants, the gap vanishes after the pension reform. All in all, the evidence in Tables 3 and 4 suggest that IAS officers who enter older are indeed less motivated in the pre-reform period but by elongating the careers of all IAS officers the pension reform reduces this source of differential performance. ${ }^{28}$

Heterogeneity analysis by entry age groups. A key heterogeneity predicted by Proposition 2 is that the reform effects should be largest for the groups most affected by the reform. Figure 6 shows the number of years a given IAS officer is formally eligible for promotion to the highest payscale by age at entry. Prior to the pension reform, individuals who entered the IAS at age 28 or 29 were mechanically capped out of the highest payscale. Under the old retirement age of 58 , these officers had to retire by the time they served for more than 30 years and hence qualified for the promotion to the top. The pension reform, extending the retirement age by two years, therefore lifted this cap for this marginal group. In contrast, while the reform also extended the career of those entering at 30 or more years of age by 2 years, this older age group is infra-marginal in that it remains mechanically

\footnotetext{
${ }^{28}$ We conducted heterogeneity tests to explore channels through which these incentive responses may be driven. We find no evidence that the reform effects differ by the relative improvement in test scores during training vs. entry exam (a proxy for intrinsic motivation), caste status, rural background, or elite schooling. The reform effects are larger for officers allocated to states with higher corruption levels, as measured by the 2005 TI corruption index (Appendix Table A14). Finally, we find no evidence that reaching the highest payscale is associated with a greater likelihood to be known by the survey respondents.
} 
excluded from the highest payscale post-reform.

Hence, in Table 5, we break down the impact of the reform into (i) those who were uncapped both before and after the reform (entry age 22-27) (ii) those who were capped before and uncapped after the reform (entry age 28-29; labeled as "marginal" group) and (iii) those who remain capped before and after the reform (30+; labeled as "too old" group). We find that the average impact in Table 4 is mainly driven by the 28-29 age at entry bin. In contrast, the impact of the reform is statistically the same for the two inframarginal groups (i.e. those too young, and those too old at entry), except for the probity outcomes (Column 2 ). For overall performance, we also reject that the pension reform effect is statistically smaller than the effect for the inframarginal older group. Overall, these non-linearities are particularly compelling as it is exactly the marginal age at entry group which appears affected by the reform. ${ }^{29}$

Additional robustness checks. Appendix Table A12, Panel A reproduces the effectiveness analysis from Panel A of Table 4 separately by caste category (general caste, OBC and SC/ST). Recall that the maximum age at entry differs across these categories: it is 30 years old for general caste, 32 years old for OBC and 35 years old for SC/ST. The results from Table 4 replicates both within the subset of OBC officers and the subset of SC/ST IAS officers. However, the results do not replicate when we restrict the sample to general caste officers. We do not view this finding as surprising given the much lower average age at entry in this group and the patterns discussed in Table 5: the bulk of general caste IAS officers $(80 \%)$ entered aged $23-27$, which means that most of the variation in age at entry in this group is inframarginal. We also show that the pension reform effects remain when we restrict the sample to the subset of officers whose exam scores would have qualified them to enter the IAS absence the quotas, as well when we restrict the sample to the subset of officers that entered at 30 years of age or less (Appendix Table A12, Panel B). We also conduct placebo exercises to ensure that the reform effects are indeed driven by the 1998 pension reform rather than other policy changes. In particular, we find no evidence that civil service reforms such as the Pay Commissions in 1986, 1996, or 2008 differentially affected older vs. younger entrants (Appendix Table A13). We also consider the possibility of differential representation in our 360 survey of younger and older officers before and after the pension reform. We test and fail to reject that differences in non-response rates between older and younger entrants change markedly after the reform (Appendix Table A2).

Finally, we consider the possibility that our findings could reflect differential self-selection into the IAS by age at entry associated with the pension reform (Proposition 1). We can further assess the relevance of the self-selection mechanism by directly comparing observable background characteristics of IAS officers by age at entry, separately for the pre- and

\footnotetext{
${ }^{29}$ The same pattern emerges using more flexible specifications to account for the entry age specific reform effects (See Appendix Figure B4). By comparing older and younger entrants, a related concern is that the reversal of the performance gap post-reform may reflect younger entrants being disincentivized due to increased competition. In Appendix Figure B3, we plot the effectiveness levels by age at entry bins for different years of intake. If anything, the figure suggests an increase in effectiveness post-reform across all age at entry groups. The larger increase among the marginal group we estimate would therefore even understate the impact of the reform.
} 
post-reform cohorts. We do this in Appendix Table A10. Overall, we do not observe much difference in how observable background characteristics correlate with age at entry (Column 2 ) or with belonging to the marginal age at entry group (28-29; Column 3) between the preand post-reform periods. In particular, we are unable to jointly reject that these differences do not change after the reform. Of course, the rich and complex dimensions of ability and type that drive the decision to apply to the IAS are not all observable. We hence do not view the evidence of Appendix Table A10 as definitive and provide next an additional test that explicitly holds selection constant.

\subsection{Test 3: Suspensions as an alternative measure of performance}

While capturing five dimensions of individual performance, the 360 scores also have limitations. A first potential concern relates to the quality of subjective ratings, and whether these perceptions indeed reflect actual performance differences. ${ }^{30}$ A second concern relates to the purely cross-sectional nature of the 360 performance data and how this may interfere with the measurement of the impact of the pension reform. Recall that all 360 scores were collected in 2012-13, i.e. in the post-pension reform period. In other words, all rated officers evaluated in 2012-2013 were operating under the extended pension age regime. The variation we exploit in Tables 4 and 5 is that some of the officers were selected into and worked in the IAS under the old pension regime while others were selected into and only served under the new regime. Ideally, we would also like to directly measure differential performance by age at entry, with performance directly measured under the old pension regime versus the new pension regime.

To address both of these concerns, we turn to administrative data on suspensions. Unlike the subjective assessments, data on suspensions is available for all IAS officers, providing an additional robustness check to alleviate concerns of sample selectivity. In particular, using the publicly available executive record sheets, we can study suspensions for all centrally recruited IAS officers over the period 1980-2012, the period for which the executive record sheets cover all IAS officers. Most importantly, to rule out selection concerns, the panel structure allows us to rule out self-selection by comparing differences in suspension rates between older versus younger entrants who entered the IAS prior to the pension reform. We can also partial out time-invariant officer-level heterogeneity, alleviating remaining concerns that our cross-sectional results are driven by unobserved correlates of age at entry.

As Appendix Table A5 shows, reassuringly, officers that have been suspended in the past are indeed perceived to perform worse on all five 360 dimensions. Officers that are under suspension in 2012-2013 are rated as less effective, more corrupt, less able to withstand political pressure, less pro-poor and have lower overall evaluation ratings. While objective in terms of measurement, these measures however have their own limitations as suspensions

\footnotetext{
${ }^{30}$ While systematic biases might likely exist in the ratings when it comes to background characteristics (e.g. negative views against women or minority castes might translate into negative subjective performance assessment absent evidence for such negative assessments), it is more difficult to think about such systematic biases driving the ratings for a variable such as age at entry $\times$ pension reform. In other words, while there might be unfair discrimination against some groups of officers, it is difficult to imagine what would drive systematic biases against older officers after the reform.
} 
may be politically motivated. An officer that is unwilling to go along with the corruption of top state politicians, for example, may be more likely to be suspended. Suspensions are also rare events and hence would only provide a very crude measure for an officer's effectiveness. In fact, it is our lack of confidence in what these measures are capturing that originally motivated the plan to carry out the 360 degree evaluation.

Table 6 presents our analysis of the suspension data. We extend the cross-sectional specification from equation (5) to the panel setting. For individual $i$ in state $s$ in year $t$, we estimate the following regression:

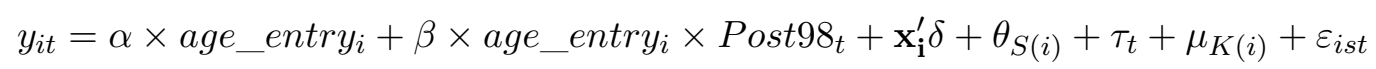

where the dependent variable $y_{i t}$ is a dummy variable that equals 1 if officer $i$ was suspended in year $t$, and 0 otherwise. The main coefficient of interest $\beta$ captures the differential impact of age at entry on the propensity to be suspended after 1998. The standard errors are clustered at the individual-level to take into account the serially correlated nature of the panel data. The regression also includes state fixed effects $\left(\theta_{s}\right.$ where $S(i)=s$ returns the allocated state of the officer $i$ ), year fixed effects $\left(\tau_{t}\right)$ and cadre fixed effects $\left(\mu_{K(i)}\right.$ where $K(i)=k$ returns the year of intake for officer $i$ ). The vector $\mathbf{x}_{\mathbf{i}}$ contains flexible dummies for each year of experience and a dummy for female. ${ }^{31}$ Identical to the sampling frame of our 360 measures, we estimate equation (6) on the full panel of IAS officers covering all centrally recruited IAS officers allocated to the 14 main states of India over the period 1980-2012 with at least 8 years of service. ${ }^{32}$

We start in Table 6, Column 1 by reporting on the relationship across all years (e.g. pre and post-pension reform years) between age at entry and likelihood of suspension in a given year. Consistent with the findings in Table 3, we find that IAS officers that enter the service older are more likely to be suspended in any given year. Column 2 also focuses on the across-year variation but leverages the non-linear relationship between the probability of reaching the top and age at entry that was observed in Figure 2. ${ }^{33}$ In particular, as in Column 4 of Table 3, we compute, based on age at entry, the probability of reaching the top of the bureaucracy for all officers in the pre-reform period. Another benefit of focusing on the probability of reaching the top by age at entry is that we can also linearly control for age at entry and hence directly account for alternative explanations that may drive a more linear negative correlation between age at entry and performance. Again, we find that a positive correlation between "reaching top" and bureaucratic performance: officers that are less career-capped are also less likely to be suspended in any given year. On average, an uncapped IAS officer is about $0.65 \%$ point less likely to be suspended than

\footnotetext{
${ }^{31}$ The individual level controls are limited when we extend the analysis to all centrally recruited officers over the period 1980-2012 as our background characteristics only go back to 1975 and therefore do not cover many of the older officers in this sample.

${ }^{32}$ We exclude from the sample observations in which the officer is older than 58 , the retirement age before the pension reform. This ensures that our results are not contaminated by the fact that officers are mechanically older in the post-pension reform period than in the pre-pension reform period.

${ }^{33}$ In the panel setting, we use the probabilities of reaching the top computed based on the pre-reform cohorts (Appendix Table A8).
} 
a career constrained officer. Compared to the unconditional probability of being suspended $(0.95 \%)$, this decline is economically large. The coefficient is insignificant once we control for linear age at entry but remains, in terms of point estimate, nearly identical (Column 3).

Column 4 presents the result of the estimation of equation (6) above. Given the low number of suspensions, breaking down older and younger entrants by pre and post-reform further reduces the variation in suspensions, resulting in noisy estimates. While older entrants are less likely to be suspended post-reform - consistent with the analysis in Tables 4 and 5 - the estimated $\beta$ coefficient is not statistically significant. In Column 5 , we further allow for the effect of age at entry on suspension to follow a linear time trend. Again, we find a positive effect of age at entry on suspension in the pre-reform years and evidence that the effect is smaller in the post-reform years. Given the noisy estimates, the estimated $\beta$ coefficient however remains statistically insignificant.

Finally, in the last two columns of Table 6, we fully exploit the panel structure of the data by adding individual fixed effects to equation (6). The benefit of controlling for individual officer fixed effects is that we can hold selection into the IAS constant and hence focus on changes in behavior (e.g. suspension) for a given officer after the pension reform. We can also, by focusing on the subset of officers that join the IAS under the old pension regime as we do in Column 7, see how the odds of suspension for these officers change after the reform based on their age at entry. In both columns, we find again a relatively larger reduction in the likelihood of suspension post pension reform among those officers that entered old into the IAS and were more likely to be career-capped under the old pension regime. Despite the more stringent test, the point estimates are if anything larger than in Column 5, and are statistically significant at the 10 percent level. The results in these last two columns suggest that the pension reform is improving the performance of IAS officers that would have been career-capped under the old regime by changing their behavior.

To further assess whether the results in Table 6 are indeed driven by the pension reform, we also estimate a more flexible version where we allow the age at entry coefficient to vary year by year. Figure 8 summarizes the results by plotting the estimated coefficients of age at entry for each year. The figure provides evidence consistent with the view that the diminishing effect of age at entry on suspension coincides with the pension reform. While the impact of age at entry is flat over time in the pre-reform period, we observe a large and discontinuous decrease after the pension reform. Overall, the fact that the pattern of effects line up across subjective and objective performance measures is reassuring and adds to our confidence that IAS officers are indeed incentivised by having a higher probability of reaching the uppermost echelon of the bureaucracy.

\subsection{Test 4: Cohort entry age composition, reform and performance}

In all of the tests performed so far, a concern remains that the variation we exploit in age at entry, even when this variation is interacted with the pension reform, may also be picking up on other unobserved factors that drive a relationship between individual effectiveness and age at entry post-reform. In this section, we therefore propose to exploit a different source 
of variation in career incentives across IAS officers. In particular, we exploit variation in the age composition of the set of officers that are allocated to a given cadre in each cohort. As described in Section 2.1, the allocation of officers to a given cadre (e.g. state) in each year follows a rule-based process that results in a quasi-random allocation of officers across states (see Appendix C1 for details). This means that, holding an officer's age at entry and the size of his or her cohort (i.e. total number of officers allocated to a cadre in a year) constant, there will be as good as random variation in the share of officers in the batch that are younger or older than the given officer. This variation can be exploited to assess the impact of the promotion rigidity on effectiveness. Intuitively, having many officers in one's cohort that will reach retirement age later than oneself decreases one's chance of reaching the highest bureaucratic echelons while having many officers in one's cohort that will reach retirement age earlier than oneself increases one's chance of reaching the highest bureaucratic echelons. Indeed, in Appendix Figure B1 we show those who enter with a larger number of younger IAS officers are less likely to reach the top payscales. Hence, we would expect an officer to perform worse as the number of younger officers in his or her cohort increases. The appeal of this additional test is that it can be implemented by holding constant age at entry as the test only relies on the comparison of relative age among officers in the same cohort.

Appendix Table A11 formally tests for the quasi-random allocation of the IAS officers across the 14 main states of India. For this table, the sample of officers is restricted to the group for which we have rich individual background data - those officers we observe in the descriptive rolls and internal ranking data. This corresponds to all intake years between 1972 and 2005. We regress individual officers' characteristics on assignment state fixed effects and entry year fixed effects. We then test for the equality of the estimated state fixed effects. The corresponding $p$-values of the test are presented in Column 1 of Appendix Table A11. Based on our rich set of observable individual characteristics, we cannot statistically reject that states receive, on average, officers that are statistically indistinguishable as regards age at entry, gender, rural/urban background, caste affiliation, education, work experience, scores on the entry exam and training marks.

We then proceed in Panel A of Table 7 by testing whether officers that have a larger number of younger officers than them assigned to their cadre at the time of entry into the IAS receive lower performance ratings. ${ }^{34}$ The regressions we estimate in Columns 1 to 5 include the same of controls as in Columns 3 and 4 of Table 3. In particular, we include as controls all individual background characteristics, survey respondent fixed effects, as well as fixed effects for the state-specific cohort an officer entered in. Importantly, the regression also includes age at entry fixed effects.

We find that officers who entered at the same age but have a larger number of younger officers in their cohort are deemed statistically significantly less effective (Column 1) and less able to withstand illegitimate political pressure (Column 3). While the remaining performance measures are insignificant, the point estimates are negative. In Panel B of

\footnotetext{
${ }^{34}$ Given the data limitations in the suspensions measure discussed in Section 3.4, we conduct this analysis only for the 360 scores.
} 
Table 7, we then ask whether the pension reform succeeded in weakening the disincentive effects associated with competing with a larger number of younger IAS officers. We do this by further interacting "number of younger officers" with a dummy that equals 1 for the post-98 cohorts. Mirroring the specification in Column 5, Table 4, we also fully interact all background characteristics with the post-98 cohorts dummy. Consistent with the pension age extension relaxing some of the constraints of competing with a larger number of younger officers, the estimated coefficent on "number of younger officers" interacted with the post-98 cohorts dummy is positive and statistically significant (Column 3-5).

In our view, while holding constant the entry age of officers, a drawback of this empirical exercise is that cohort composition may affect performance through other channels (e.g. peer effects). It is however reassuring for our preferred interpretation that the pension reform appears to alleviate the negative effect. Overall, we view the evidence in Table 7 as providing complementary evidence on how the combination of seniority-based promotion and a fixed retirement age may distort the career incentives of officers that join the IAS at a relatively older age. The main benefit of this complementary evidence is that we obtain these results not from age at entry variation (which we hold constant), but from variation in the age at entry composition in a cohort induced by the IAS rule regarding the allocation of officers to states.

\section{Conclusion}

The organization of the state has attracted increasing attention within economics as a central determinant of economic performance (Besley and Persson 2009; Finan et al 2015). A recent wave of papers has studied the selection (Ashraf et al. 2016; Callen et al. 2015; Dal Bo et al. 2013; Deserranno 2017; Weaver 2017) and incentives (Callen et al. 2014; Khan et al. 2015; Ornaghi 2016; Nath 2016, Gulzar and Pasquale 2017; Rasul and Rogger 2017) of frontline providers. Senior bureaucrats, who tend to be generalists performing a range of tasks over their careers, however, have remained understudied owing to the difficulty of measuring their performance. These bureaucrats form the backbone of the state staying in post as politicians churn in and out of office. Yet we understand very little about what motivates them or about how they can be made more effective.

By fielding a large-scale survey in fourteen states of India in 2012-13, we introduce a new measurement framework that has enabled us to open the black box of what determines bureaucrat performance. The survey enables us to study the link between career incentives and bureaucrat peformance in a way that had not been possible before. Given how understudied bureaucrats are and how central they are to the implementation of policy being able to measure their effectiveness and to understand the factors that influence it represents an important undertaking.

The central contribution of this paper is to point to the career incentive of reaching the top of a public organization as a poweful determinant of bureaucrat performance. As our theoretical model makes clear, in public organizations where performance is not di-

rectly linked to wages (within a payscale) but does affect the prospects of reaching the 
senior-level payscales (which itself carries significant pecuniary and non-pecuniary benefits), career incentives can become a powerful determinant of effort. Rules and policies that dim these "glittering prize" incentives, such as seniority based promotion, will then serve to demotivate.

By mapping our model onto a set of estimating equations utilising our survey and administrative data we uncover evidence that "glittering prize" incentives affect bureaucrat performance. Our results shine light on the costs associated with rigid promotion rules that prevent older entrants from reaching the highest echelons of the bureaucracy. By making the "glittering prize" of reaching the senior-most payscale more attainable we find that the pension reform closed the gap in performance between older and younger entrants. Our results therefore provide evidence that personnel policies can be a powerful driver of organizational performance.

The fact that the IAS is organised like many other professional civil services around the world gives our findings a wider resonance. Across a wide range of civil services entry is competitive, promotion is constrained by seniority, jobs are for life and retirement occurs at a fixed age. This implies that the disincentive that arises from being unable to reach the uppermost echelon of the bureaucracy before one retires may be relevant in a wide variety of settings. Understanding these costs and gaining insights into how bureaucrats might be better motivated represents an important undertaking not just in professional civil services but also in a much wider set of public organizations which are organised like the IAS and which supply services ranging from health and education through to diplomatic services.

These costs, which derive from public organizations being configured differently from private and political organizations, however, must be set against the potential benefits of clear progression rules in terms of avoiding the patronage and favoritism which characterized earlier bureaucracies (Northcote and Trevelyan 1854). The rule based nature of professional, modern bureaucracies arose in large part because of the difficulties in measuring the performance of generalist civil servants who performed a range of duties over their careers (Weber 1922). Future work will therefore need to focus on how best to protect the benefits of this system whilst minimizing costs. Our analysis of the value of extending bureaucrat careers through a pension reform is a first step in this direction but a whole range of options - fast tracking, narrowing the entry window, fixed tenures as opposed to fixed retirement ages, recruitment of officers from outside at all levels and firing of poor performers - all deserve further analysis as means of improving bureaucrat performance. We are very much in the infancy of understanding how to best to motivate bureaucrats and so this stands out as an important area for future work.

By examining the incentives of civil service leaders through the prism of organizational economics (Baker et al. 1994; Dewatripont 1999; Gibbons and Roberts 2013; Bloom et al. 2013), this paper connects the literatures on private sector (Bertrand and Schoar 2003; Kaplan et al. 2012), political (Jones and Olken 2005; Yao and Zhang 2015; Persson and Zhuravskaya 2016; Jia 2017; Martinez-Bravo et al. 2017) and public sector (Xu 2018) leaders. These different types of leaders all run large organizations and so the career incentives they 
face may impact both organizational performance and a wider set of economic outcomes. The IAS officers we study, for example, hold positions at the apex of government that grant them significant influence over the implementation of policies, rules and regulations in a country of over a billion people.

Another line of future work could therefore focus on exploring the mechanisms through which civil service leaders can affect aggregate economic outcomes. For example, the superior performance we observe post-reform for older entrants into the IAS leaves open the intriguing question on the link between the performance of individual bureaucrats and the aggregate performance of the geographies over which they exert jurisdiction. More generally, work that connects the recent literature on the incentives and selection of bureaucrats with the older literature that sees bureaucrats as central to the industrialization and growth processes (Weber 1922, Tullock 1965, Rauch 1995, Rauch and Evans 2000) has the potential to substantially deepen our understanding about the role of the public sector in development.

\section{Bibliography}

Administrative Reform Commission (2008) "Refurbishing of Personnel Administration Scaling New Heights", Tenth Report, Second Administrative Reforms Commission

Altonji, J. G., T. E. Elder, and C. R. Taber (2005) "Selection on Observed and Unobserved Variables: Assessing the Effectiveness of Catholic Schools", Journal of Political Economy, 113, 151-184.

Aghion, P. and Burgess, R. and Redding, S. J. and Zilibotti, F. (2008): "The Unequal Effects of Liberalization: Evidence from Dismantling the License Raj in India", American Economic Review, vol. 98 (4), 1397-1412.

Ashraf, N. and Bandiera, O. and Lee, S. (2016) "Do-gooders and Go-getters: Career Incentives, Selection and Performance in Public Service Delivery", mimeo

Bai, Y. and Jia, R. (2016) "Elite Recruitment and Political Stability: The Impact of the Abolition of China's Civil Service Exam", Econometrica, vol. 84 (2), 677-733.

Baker, G. and Gibbons, R. and Murphy, K. (1994) "Subjective Performance Measures in Optimal Incentive Contracts", Quarterly Journal of Economics, vol. 109 (4), 1125-1156.

Bekke, P. and Toonen, T. and Perry, J. (1996) "Civil Service Systems in Comparative Perspective", Indiana University Press.

Bertrand, M. and Schoar, A. (2003) "Managing with Style: The Effect of Managers on Firm Policies", Quarterly Journal of Economics, vol. 118 (4), 1169-1208. 
Bertrand, M. (2009) "CEOs", Annual Review of Economics, vol. 1, 121-150.

Besley, T. and Montalvo, J. and Reynal-Querol, M. (2011) "Do Educated Leaders Matter?" The Economic Journal, vol. 121 (554), 205-227.

Besley, T. and Persson, T. (2009) "The Origins of State Capacity: Property Rights, Taxation and Politics", American Economic Review, vol. 99 (4), 1218-44.

Bloom, N. and Eifert, B. and Mahajan, A. and McKenzie, D. and Roberts, J. (2013) "Does Management Matter? Evidence from India", vol. 128 (1), 1-51.

Bloom, N. and Saddun, R. and Van Reenen, J. (2016) "Management as a Technology?", CEP discussion paper No. 1433,

Callen, M. and Gulzar, S. and Hasanain, A. and Khan, Y. (2014) "The Political Economy of Public Employee Absence: Experimental Evidence from Pakistan", mimeo

Callen, M. and Gulzar, S. and Hasanain, A. and Khan, Y. and Rezaee, A. (2015) "Personalities and Public Sector Performance: Evidence from a Health Experiment in Pakistan", mimeo

Dal Bo, E. and Finan, F. and Rossi, M. A. (2013) "Strengthening State Capabilities: The Role of Financial Incentives in the Call to Public Service", The Quarterly Journal of Economics, vol. 128 (3), 1169-1218.

Deserranno, E. (2017) "Financial Incentives as Signals: Experimental Evidence from the Recruitment of Health Promoters", American Economic Journal: Applied

Dewatripont (1999) "The Economics of Career Concerns, Part II: Application to Missions and Accountability of Government Agencies", Review of Economic Studies, vol. 66 (1), 199-217.

Fulton, J. (1968) "The Civil Service. Vol 1. Report of the Committee 1966-68", HMSO

Finan, F. and Olken, B.and Pande, R. (2015) "The Personnel Economics of the State", NBER working paper No. 21825.

Frederiksen, A. and Lange, F. and Kriechel, B. (2017) "Subjective Performance Evaluations and Employee Careers", Journal of Economic Behavior and Organizations, vol. 134, 408-429. 
Gibbons, R. and Roberts, J. (2013) "The Handbook of Organizational Economics", Princeton University Press.

Gulzar, S. and Pasquale, B. (2017) "Politicians, Bureaucrats and Development: Evidence from India”, American Political Science Review, vol. 111 (1), 162-183.

Holmstrom, B. and Milgrom, P. (1991) "Multitask Principal-Agent Analyses: Incentive Contracts, Asset Ownership, and Job Design", Journal of Law, Economics and Organizations, vol. 7, 24-52.

Iyer, L. and Mani, A. (2012) "Travelling Agents: Political Change and Bureaucratic Turnover in India", Review of Economics and Statistics, vol. 94 (3), 723-729.

Jia, R. (2017) "Pollution for Promotion", mimeo

Jones, C. and Olken, B. (2005) "Do Leaders Matter? National Leadership and Growth Since World War II", The Quarterly Journal of Economics, vol. 120 (3), 835-864.

Kaplan S., Klebanov, M. and Sorenson, M. (2012) "Which CEO Characteristics and Abilities Matter?", Journal of Finance, vol. 67 (3), 973-1007.

Ke, R. and Li, J. and Powell, M. (2016), "Managing Careers in Organizations", Journal of Labor Economics, forthcoming.

Kirk-Greene, A. (2000) “Britain’s Imperial Administrators, 1858-1966”, Palgrave

Khan, A. and Khwaja, K. and Olken, B. (2015) "Tax Farming Redux: Experimental Evidence on Performance Pay for Tax Collectors", Quarterly Journal of Economics, vol. 131 (1), 219-271.

Martinez-Bravo, M. and Mukherjee, P. and Stegman, A. (2017) "The Non-Democratic Roots of Elite-Capture: Evidence from Soeharto Mayors in Indonesia", Econometrica, vol. 85 (6), 1991-2010.

Milgrom, P. (1988) "Employment Contracts, Influence Activities and Efficient Organization Design", Journal of Political Economy, vol. 96 (1), 42-60.

Nath, Anusha (2016) "Bureaucrats and Politicians: How Does Electoral Competition Affect Bureaucratic Performance?", mimeo

Northcote, S. and Trevelyan C. E. (1854) "Report on the Organization of the Permanent 
Civil Service", House of Commons, Her Majesty's Stationery Office

Persson, P. and Zhuravskaya, E. (2016) "The Limits of Career Concerns in Federalism: Evidence from China", Journal of European Economic Association, vol. 14(2), 338-374.

Prendergast, C. and Topel, R. (1996) "Favoritism in Organizations", Journal of Political Economy, vol. 104 (5), 958-978.

Prendergast, C. (1999) "The Provision of Incentives in Firms", Journal of Economic Literature, vol. 37 (1), 7-63.

Ornaghi, A. (2016) "Civil Service Reforms: Evidence from U.S. Police Departments", mimeo

Oster, Emily (2017) "Unobservable Selection and Coefficient Stability: Theory and Evidence", Journal of Business \& Economic Statistics, 1-18.

Oyer, P. and Schaefer, S. (2010) "Personnel Economics: Hiring and Incentives". In the Handbook of Labor Economics, edited by O. Ashenfelter and D. Card. Elsevier.

Rasul, I. and Rogger, D. (2017) "Management of Bureaucrats and Public Service Delivery: Evidence from the Nigerian Civil Service", Economic Journal

Rauch, J. E. (1995) "Bureaucracy, Infrastructure and Economic Growth: Evidence from U.S. Cities during the Progressive Era", American Economic Review, vol. 85 (4), 968-979.

Rauch, J. E. and Evans, P. B. (2000) "Bureaucratic Structure and Bureaucratic Performance in Less Developed Countries", Journal of Public Economics, vol. 75(1), 49-71.

Tullock, G. (1965) "The Politics of Bureaucracy", Washington: Public Affairs Press.

Van der Meer, F. and Raadschelders, F. and Toonen, J. (2015) "Comparative Civil Service Systems in the 21st Century", Palgrave Macmillan.

Weaver, J. (2017) "Jobs for Sale: Corruption and Misallocation in Hiring", mimeo

Weber, M. (1922) "Economy and Society", 4th Edition (republished 1956). Tübingen.

Xu, G. (2018) "The Costs of Patronage: Evidence from the British Empire", American Economic Review, forthcoming 
Yao, Y. and Zhang, M. (2015) "Subnational Leaders and Economic Growth: Evidence from Chinese cities", Journal of Economic Growth, vol. 20(4), 405-436. 
Table 1: Descriptive statistics of subjective evaluations

\begin{tabular}{lccccc}
\hline \hline & $(1)$ & $(2)$ & $(3)$ & $(4)$ & $(5)$ \\
& Mean & SD & Ratings & Officers & Coverage \\
\hline Effectiveness on the job & 3.730 & 1.077 & 17,753 & 1,472 & $72.01 \%$ \\
Probity of IAS officer & 3.670 & 1.105 & 15,153 & 1,451 & $70.98 \%$ \\
Withstanding illegitimate pressure & 3.523 & 1.094 & 16,728 & 1,471 & $71.96 \%$ \\
Sensitive towards poorer & 3.527 & 1.141 & 17,047 & 1,471 & $71.96 \%$ \\
Overall rating & 3.646 & 1.057 & 17,698 & 1,472 & $72.01 \%$ \\
\hline \hline
\end{tabular}

Subjective evaluations for the cross-section of IAS officers in 2012-13. Reporting the descriptive statistics (mean and standard deviation) for the performance scores, where the scores range from 1 (lowest) to 5 (highest). The questions used to elicit the subjective ratings are: How would you rate his/her effectiveness in his/her assignment? How much do you feel the officer uses his/her official position for making money? How much do you feel this officer can withstand illegitimate political pressure? How sensitive is this officer to the needs of the poor and weaker sections in society? What is your overall rating of this officer? Column 3 and 4 report the total number of ratings and the total number of rated officers. Column 5 reports the coverage rate for the sample population of all active, centrally recruited IAS officers with at least 8 years of tenure in $2012 / 13$. 
Table 2: Individual characteristics of IAS officers in 2012

\begin{tabular}{lccccccc}
\hline \hline & $(1)$ & $(2)$ & $(3)$ & $(4)$ & $(5)$ & $(6)$ \\
\cline { 5 - 6 } & & & \multicolumn{3}{c}{ Percentile } \\
\cline { 5 - 6 } & Mean & SD & $25 \%$ & $50 \%$ & $75 \%$ & Obs. \\
\hline Age at entry & 25.474 & 2.088 & 24 & 25 & 27 & 1,472 \\
Female & 0.141 & 0.349 & 0 & 0 & 1 & 1,472 \\
Other backward caste (OBC) & 0.081 & 0.273 & 0 & 0 & 0 & 1,472 \\
Scheduled caste (SC) & 0.141 & 0.349 & 0 & 0 & 1 & 1,472 \\
Scheduled tribe (ST) & 0.052 & 0.222 & 0 & 0 & 0 & 1,472 \\
Urban background & 0.737 & 0.439 & 0 & 1 & 1 & 1,472 \\
Academic distinction & 0.326 & 0.468 & 0 & 0 & 1 & 1,472 \\
STEM or Economics degree & 0.602 & 0.489 & 0 & 1 & 1 & 1,472 \\
Previous job: Education/research & 0.168 & 0.374 & 0 & 0 & 1 & 1,472 \\
Previous job: Finance/banking & 0.056 & 0.230 & 0 & 0 & 1 & 1,472 \\
Previous job: Private/SOE & 0.121 & 0.326 & 0 & 0 & 1 & 1,472 \\
Previous job: Public sector & 0.324 & 0.468 & 0 & 0 & 1 & 1,472 \\
Previous job: Public AIS & 0.033 & 0.181 & 0 & 0 & 0 & 1,472 \\
UPSC score (standardized) & 0.070 & 0.913 & -0.187 & 0.147 & 0.505 & 1,472 \\
Training score (standardized) & 0.048 & 0.946 & -0.476 & 0.092 & 0.646 & 1,472 \\
1[Training > UPSC score] & 0.328 & 0.469 & 0 & 0 & 1 & 1,472 \\
Cohort size & 7.334 & 3.971 & 4 & 7 & 9 & 1,472 \\
Younger peers & 2.294 & 2.513 & 0 & 2 & 3 & 1,472 \\
\hline \hline
\end{tabular}

Descriptive statistics (mean, standard deviation and percentiles) of IAS officers in 2012-13. Sample covers the cross-section of centrally recruited IAS officers in 2012-13 for which performance ratings have been collected. Age at entry is the age the IAS officer entered the service. Urban background denotes officers from urban areas, Academic distinction is a dummy for having received an academic distinction, as measured by a first-class honours in undergraduate or a distinction in graduate studies (equivalent to a GPA above 3.0). STEM is a dummy for graduates of Science, Technology, Engineering and Mathematics and Economics degrees. Previous job denotes the sector of employment previous to entry into IAS (Education/research, Finance/banking, Private sector/State-owned-enterprise, Public sector-Non All India Service, Public sector-All India Service). UPSC score is the (intake year) standardized score in the competitive entry examination. Training score is the (intake year) standardized score in the training period. $\mathbf{1}$ [Training $>$ UPSC score] is a dummy that is 1 if the officer improved the relative rating between training and competitive exam. Cohort size is the overall number of officers that entered the IAS in the same year and were allocated to the same state. Younger peers is the number of those who are younger than the officer. 
Table 3: Performance, age at entry and probability of reaching top

\begin{tabular}{|c|c|c|c|c|c|}
\hline Panel A & $\overline{(1)}$ & $\overline{(2)}$ & $\overline{(3)}$ & $\overline{(4)}$ & $\overline{(5)}$ \\
\hline & \multicolumn{5}{|c|}{ Effectiveness (1 low, 5 high) } \\
\hline Mean of dep. var & 3.734 & 3.734 & 3.734 & 3.734 & \\
\hline Age at entry & $\begin{array}{c}-0.014^{* * *} \\
(0.005)\end{array}$ & $\begin{array}{c}-0.013^{* *} \\
(0.005)\end{array}$ & $\begin{array}{c}-0.013^{* *} \\
(0.006)\end{array}$ & & $\begin{array}{c}0.019 \\
(0.018)\end{array}$ \\
\hline Reaching top & & & & $\begin{array}{c}0.118^{* * *} \\
(0.044)\end{array}$ & $\begin{array}{l}0.253^{*} \\
(0.138)\end{array}$ \\
\hline Respondent FEs & $\mathrm{Y}$ & $\mathrm{Y}$ & $\mathrm{Y}$ & $\mathrm{Y}$ & $\mathrm{Y}$ \\
\hline State $\times$ Intake year FEs & & $\mathrm{Y}$ & $\mathrm{Y}$ & $\mathrm{Y}$ & Y \\
\hline Controls & & & Y & Y & $\mathrm{Y}$ \\
\hline Sample & \multicolumn{5}{|c|}{ Pre-reform cohorts } \\
\hline Observations & 15,396 & 15,396 & 15,396 & 15,396 & 15,396 \\
\hline Panel B & $\overline{(1)}$ & $\overline{(2)}$ & $\overline{(3)}$ & $\overline{(4)}$ & $\overline{(5)}$ \\
\hline Mean of den yar & Effective & Probity & Pressure & Pro-poor & Overall \\
\hline Age at entry & $\begin{array}{c}-0.013^{* *} \\
(0.006)\end{array}$ & $\begin{array}{l}-0.008 \\
(0.007)\end{array}$ & $\begin{array}{c}-0.014^{* *} \\
(0.005)\end{array}$ & $\begin{array}{l}-0.004 \\
(0.005)\end{array}$ & $\begin{array}{c}-0.011^{*} \\
(0.006)\end{array}$ \\
\hline Respondent FEs & $\mathrm{Y}$ & $\mathrm{Y}$ & $\mathrm{Y}$ & $\mathrm{Y}$ & $\mathrm{Y}$ \\
\hline State $\times$ Intake year FEs & Y & Y & $\mathrm{Y}$ & $\mathrm{Y}$ & $\mathrm{Y}$ \\
\hline Controls & $\mathrm{Y}$ & Y & $\mathrm{Y}$ & Y & $\mathrm{Y}$ \\
\hline Sample & \multicolumn{5}{|c|}{ Pre-reform cohorts } \\
\hline Observations & 15,396 & 13,129 & 14,512 & 14,782 & 15,340 \\
\hline
\end{tabular}

Unit of observation is the score for a given IAS officer in 2012-13 with at least 8 years of tenure. Relating the cross-section of perceived effectiveness (Panel A), probity, ability to withstand illegitimate political pressure, pro-poor orientedness and overall scores (Panel B) to age at entry and the probability of reaching the top. Age at entry is the age the IAS officer entered the service. Reaching top is the share of retired officers who reached the top payscale (Chief Secretary level, requiring at least 30 years of tenure) for a given age at entry (see Appendix Table A8). Respondent FEs are fixed effects for each survey respondent. State $\times$ Intake year FEs are fixed effects for the state-specific cohort the officer entered in. Individual controls are: female dummy, caste dummies (OBC, SC, ST), a dummy for coming from an urban area, having received an academic distinction, a STEM or Economics degree, having worked in education/research, private sector/SOEs, public sector, public AIS, standardized scores for the (UPSC) entry and training scores, as well as a dummy that is 1 if the officer improved the ranking in the training relative to the entry exam. The sample comprises all IAS officers in 2012-13 who entered before the pension reform of 1998. Standard errors are clustered at the individual-level. ${ }^{* * *} p<0.01,{ }^{* *} p<0.05$, * $p<0.1$. 
Table 4: Performance, age at entry and entering before/after the pension reform

\begin{tabular}{|c|c|c|c|c|c|}
\hline \multirow[t]{2}{*}{$\underline{\text { Panel A }}$} & $(1)$ & 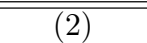 & (3) & (4) & (5) \\
\hline & \multicolumn{5}{|c|}{ Effectiveness (1 low, 5 high) } \\
\hline Mean of dep. var & 3.734 & 3.701 & 3.730 & 3.730 & 3.730 \\
\hline \multirow[t]{2}{*}{ Age at entry } & $-0.013^{* *}$ & $0.027^{*}$ & $-0.012^{* *}$ & $-0.040^{* * *}$ & $-0.040^{* * *}$ \\
\hline & $(0.006)$ & $(0.016)$ & $(0.006)$ & $(0.013)$ & $(0.012)$ \\
\hline \multirow{2}{*}{ Age at entry $\times$ Post reform cohort } & & & $0.031 * * *$ & $0.066^{* * *}$ & $0.067 * * *$ \\
\hline & & & $(0.011)$ & $(0.018)$ & $(0.020)$ \\
\hline Respondent FEs & $\mathrm{Y}$ & $\mathrm{Y}$ & $\mathrm{Y}$ & $\mathrm{Y}$ & $\mathrm{Y}$ \\
\hline State $\times$ Intake year FEs & $\mathrm{Y}$ & $\mathrm{Y}$ & $\mathrm{Y}$ & $\mathrm{Y}$ & Y \\
\hline Controls & Y & $\mathrm{Y}$ & $\mathrm{Y}$ & $\mathrm{Y}$ & Y \\
\hline & & & $\mathrm{Y}$ & $\mathrm{Y}$ \\
\hline \multicolumn{2}{|l|}{ Controls $\times$ Post reform cohort } & & & & $\mathrm{Y}$ \\
\hline Sample & Pre & Post & \multicolumn{3}{|c|}{ Pre \& post-reform cohorts } \\
\hline Observations & 15,396 & 2,186 & 17,749 & 17,749 & 17,749 \\
\hline \multirow[t]{2}{*}{$\underline{\underline{\text { Panel B }}}$} & (1) & (2) & (3) & (4) & 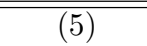 \\
\hline & Effective & Probity & Pressure & Pro-poor & Overall \\
\hline Mean of dep. var & 3.730 & 3.671 & 3.524 & 3.528 & 3.647 \\
\hline \multirow[t]{2}{*}{ Age at entry } & $-0.040 * * *$ & $-0.049 * * *$ & $-0.040^{* * *}$ & $-0.022^{*}$ & $-0.033^{* *}$ \\
\hline & $(0.012)$ & $(0.016)$ & $(0.013)$ & $(0.013)$ & $(0.014)$ \\
\hline \multirow[t]{2}{*}{ Age at entry $\times$ Post reform cohort } & $0.067^{* * *}$ & $0.076^{* * *}$ & $0.039^{* *}$ & 0.029 & $0.057 * * *$ \\
\hline & $(0.020)$ & $(0.024)$ & $(0.019)$ & $(0.020)$ & $(0.021)$ \\
\hline Respondent FEs & $\mathrm{Y}$ & $\mathrm{Y}$ & $\mathrm{Y}$ & $\mathrm{Y}$ & $\mathrm{Y}$ \\
\hline State $\times$ Intake year FEs & $\mathrm{Y}$ & $\mathrm{Y}$ & $\mathrm{Y}$ & Y & Y \\
\hline Controls & $\mathrm{Y}$ & Y & $\mathrm{Y}$ & Y & Y \\
\hline Age at entry $\times$ Intake year & $\mathrm{Y}$ & $\mathrm{Y}$ & Y & $\mathrm{Y}$ & $\mathrm{Y}$ \\
\hline Controls $\times$ Post reform cohort & $\mathrm{Y}$ & $\mathrm{Y}$ & $\mathrm{Y}$ & $\mathrm{Y}$ & Y \\
\hline Sample & & Pre \& & ost-reform & ohorts & \\
\hline Observations & 17,749 & 15,133 & 16,717 & 17,042 & 17,694 \\
\hline
\end{tabular}

Unit of observation is the score for a given IAS officer in 2012-13 with at least 8 years of tenure. Relating the cross-section of perceived effectiveness (Panel A), probity, ability to withstand illegitimate political pressure, pro-poor orientedness and overall scores (Panel B) to age at entry and cohorts entering before/after the pension reform. Age at entry is the age the IAS officer entered the service. Post reform cohort is a dummy that is 1 if the IAS officer entered in the year of the pension reform 1998 or after. Respondent FEs are fixed effects for each survey respondent. State $\times$ Intake year FEs are fixed effects for the state-specific cohort the officer entered in. Individual controls are: female dummy, caste dummies (OBC, SC, ST), a dummy for coming from an urban area, having received an academic distinction, a STEM or Economics degree, having worked in education/research, private sector/SOEs, public sector, public AIS, standardized scores for the (UPSC) entry and training scores, as well as a dummy that is 1 if the officer improved the ranking in the training relative to the entry exam. Age at entry $\times$ Intake year is the interaction between (linear) age at entry and the (linear) intake year, with the officer's year of intake centered around the pension reform of 1998. Controls $\times$ Post reform cohort interacts all individual background controls with the reform dummy. Standard errors are clustered at the individual-level. *** $p<0.01,{ }^{* *} p<0.05, * p<0.1$. 
Table 5: Performance and the impact of the pension reform by entry age bins

\begin{tabular}{|c|c|c|c|c|c|}
\hline & (1) & $(2)$ & $(3)$ & (4) & $(5)$ \\
\hline & Effective & Probity & Pressure & Pro-poor & Overall \\
\hline Mean of dep. var & 3.730 & 3.671 & 3.524 & 3.528 & 3.647 \\
\hline \multirow[t]{2}{*}{ Marginal $\times$ Post reform cohort } & $0.337 * * *$ & $0.342^{* *}$ & 0.178 & $0.251^{* *}$ & $0.404^{* * *}$ \\
\hline & $(0.124)$ & $(0.158)$ & $(0.127)$ & $(0.127)$ & $(0.138)$ \\
\hline \multirow[t]{2}{*}{ Too old $\times$ Post reform cohort } & 0.240 & $0.600^{* *}$ & 0.305 & 0.039 & 0.093 \\
\hline & $(0.194)$ & $(0.269)$ & $(0.217)$ & $(0.182)$ & $(0.196)$ \\
\hline Test $H_{0}:$ Marginal $\leq$ Too old & 0.311 & 0.734 & 0.643 & 0.125 & 0.072 \\
\hline Respondent FEs & $\mathrm{Y}$ & $\mathrm{Y}$ & $\mathrm{Y}$ & $\mathrm{Y}$ & $\mathrm{Y}$ \\
\hline State $\times$ Intake year FEs & $\mathrm{Y}$ & $\mathrm{Y}$ & $\mathrm{Y}$ & $\mathrm{Y}$ & $\mathrm{Y}$ \\
\hline Age at entry FEs & $\mathrm{Y}$ & $\mathrm{Y}$ & $\mathrm{Y}$ & $\mathrm{Y}$ & $\mathrm{Y}$ \\
\hline Controls & $\mathrm{Y}$ & $\mathrm{Y}$ & $\mathrm{Y}$ & $\mathrm{Y}$ & $\mathrm{Y}$ \\
\hline Marginal/too old $\times$ Intake year & $\mathrm{Y}$ & $\mathrm{Y}$ & $\mathrm{Y}$ & $\mathrm{Y}$ & $\mathrm{Y}$ \\
\hline Controls $\times$ Post reform cohort & $\mathrm{Y}$ & $\mathrm{Y}$ & $\mathrm{Y}$ & $\mathrm{Y}$ & $\mathrm{Y}$ \\
\hline Sample & \multicolumn{5}{|c|}{ Pre \& post-reform cohorts } \\
\hline Observations & 17,749 & 15,133 & 16,717 & 17,042 & 17,694 \\
\hline
\end{tabular}

Unit of observation is the score for a given IAS officer in 2012-13 with at least 8 years of tenure. Relating the cross-section of perceived effectiveness, probity, ability to withstand illegitimate political pressure, pro-poor orientedness and overall scores to age at entry bins (marginal/too old) and cohorts entering before/after the pension reform. Post reform cohort is a dummy that is 1 if the IAS officer entered in the year of the pension reform 1998 or after. Marginal is a dummy that is 1 for officers entering aged between $[28,29]$. The dummy too old is a dummy that is 1 if officers entered with at least 30 years of age. The omitted category are IAS officers who are aged 22-27 at entry and hence too young to be affected by the reform. Respondent FEs are fixed effects for each survey respondent. State $\times$ Intake year FEs are fixed effects for the state-specific cohort the officer entered in. Age at entry FEs are dummies for each entry age. Individual controls are: female dummy, caste dummies (OBC, SC, ST), a dummy for coming from an urban area, having received an academic distinction, a STEM or Economics degree, having worked in education/research, private sector/SOEs, public sector, public AIS, standardized scores for the (UPSC) entry and training scores, as well as a dummy that is 1 if the officer improved the ranking in the training relative to the entry exam. Marginal/too old $\times$ Intake year are the interactions between the marginal and old dummies and the (linear) intake year, with the officer's year of intake centered around the pension reform of 1998. Controls $\times$ Post reform cohort interacts all individual background controls with the reform dummy. Standard errors are clustered at the individual-level. Standard errors are clustered at the individual-level. ${ }^{* * *} p<0.01,{ }^{* *} p<0.05,{ }^{*} p<0.1$. 
Table 6: Suspension, age at entry and pension reform

\begin{tabular}{|c|c|c|c|c|c|c|c|}
\hline & (1) & $(2)$ & (3) & (4) & $(5)$ & (6) & $(7)$ \\
\hline & \multicolumn{7}{|c|}{ IAS officer is suspended $(\times 100)$} \\
\hline Mean of dep. var & 0.953 & 0.953 & 0.953 & 0.953 & 0.953 & 0.954 & 0.957 \\
\hline Age at entry & $\begin{array}{l}0.069^{*} \\
(0.035)\end{array}$ & & $\begin{array}{c}0.001 \\
(0.989)\end{array}$ & $\begin{array}{c}0.102^{* * *} \\
(0.494)\end{array}$ & $\begin{array}{c}0.133^{* *} \\
(0.059)\end{array}$ & & \\
\hline Reaching top & & $\begin{array}{c}-0.645^{* *} \\
(0.295)\end{array}$ & $\begin{array}{l}-0.637 \\
(0.612)\end{array}$ & & & & \\
\hline Age at entry $\times$ Post reform & & & & $\begin{array}{l}-0.071 \\
(0.055)\end{array}$ & $\begin{array}{l}-0.132 \\
(0.088)\end{array}$ & $\begin{array}{c}-0.184^{* *} \\
(0.093)\end{array}$ & $\begin{array}{c}-0.182^{*} \\
(0.093)\end{array}$ \\
\hline Intake year FEs & $\mathrm{Y}$ & $\mathrm{Y}$ & $\mathrm{Y}$ & $\mathrm{Y}$ & $\mathrm{Y}$ & & \\
\hline State FEs & $\mathrm{Y}$ & $\mathrm{Y}$ & $\mathrm{Y}$ & $\mathrm{Y}$ & $\mathrm{Y}$ & & \\
\hline Experience FEs & $\mathrm{Y}$ & $\mathrm{Y}$ & $\mathrm{Y}$ & $\mathrm{Y}$ & $\mathrm{Y}$ & $\mathrm{Y}$ & $\mathrm{Y}$ \\
\hline Year FEs & $\mathrm{Y}$ & Y & Y & Y & $\mathrm{Y}$ & Y & $\mathrm{Y}$ \\
\hline Age at entry $\times$ Year & & & & & $\mathrm{Y}$ & $\mathrm{Y}$ & Y \\
\hline Individual FEs & & & & & & $\mathrm{Y}$ & $\mathrm{Y}$ \\
\hline Sample & \multicolumn{6}{|c|}{ Pre \& post-reform cohorts } & Pre-reform \\
\hline Observations & 86,112 & 86,112 & 86,112 & 86,112 & 86,112 & 86,017 & 84,503 \\
\hline
\end{tabular}

Unit of observation is the IAS officer in a given year. Relating suspension to age at entry, the probability of reaching the top, and the pension reform of 1998. The dependent variable suspended is a dummy that is 1 if the IAS officer is suspended in a given year (rescaled by $\times 100$ ). Age at entry is the age the IAS officer entered the service. Reaching top is the share of pre-reform retired officers who reached the top payscale (Chief Secretary level, requiring at least 30 years of tenure) for a given age at entry (see Appendix Table A8). Post reform cohort is a dummy that is 1 if the IAS officer entered in the year of the pension reform 1998 or after. Intake year FEs are dummies for each year of intake, state FEs are dummies for the states officers are allocated in, experience are dummies for each year of tenure in the IAS, and year FEs are dummies for each year. Age at entry $\times$ Year is the (linear) interaction between age at entry and a linear time trend normalized around the pension reform year of 1998. The sample is the universe of centrally recruited IAS officers with 58 years of age or below (the pre-1998 retirement age) and having served at least 8 years in service for the period of 1980-2012. Column 7 restricts the sample to cohorts who entered before the pension reform. Standard errors are clustered at the individual-level. $* * * p<0.01,{ }^{* *} p<0.05,{ }^{*} p<0.1$. 
Table 7: Effectiveness, exposure to younger cohort members and reform

\begin{tabular}{lccccc}
\hline \hline Panel A & $(1)$ & $(2)$ & $(3)$ & $(4)$ & $(5)$ \\
Mean of dep. var & Effective & Probity & Pressure & Pro-poor & Overall \\
& 3.730 & 3.671 & 3.524 & 3.528 & 3.647 \\
\hline Younger & $-0.036^{* *}$ & -0.025 & $-0.034^{* *}$ & -0.029 & -0.021 \\
& $(0.017)$ & $(0.020)$ & $(0.016)$ & $(0.018)$ & $(0.019)$ \\
\hline Respondent FEs & $\mathrm{Y}$ & $\mathrm{Y}$ & $\mathrm{Y}$ & $\mathrm{Y}$ & $\mathrm{Y}$ \\
State $\times$ Intake year FEs & $\mathrm{Y}$ & $\mathrm{Y}$ & $\mathrm{Y}$ & $\mathrm{Y}$ & $\mathrm{Y}$ \\
Age at entry FEs & $\mathrm{Y}$ & $\mathrm{Y}$ & $\mathrm{Y}$ & $\mathrm{Y}$ & $\mathrm{Y}$ \\
Controls & $\mathrm{Y}$ & $\mathrm{Y}$ & $\mathrm{Y}$ & $\mathrm{Y}$ & $\mathrm{Y}$ \\
Sample & & Pre \& & post-reform & cohorts & \\
Observations & 17,749 & 15,133 & 16,717 & 17,042 & 17,694 \\
\hline \hline Panel B & $(1)$ & $(2)$ & $(3)$ & $(4)$ & $(5)$ \\
Mean of dep. var & Effective & Probity & Pressure & Pro-poor & Overall \\
Younger & 3.730 & 3.671 & 3.524 & 3.528 & 3.647 \\
\hline Younger $\times$ Post reform cohort & $-0.054^{* * *}$ & -0.037 & $-0.049^{* * *}$ & $-0.041^{* *}$ & $-0.046^{* *}$ \\
& $(0.019)$ & $(0.023)$ & $(0.018)$ & $(0.021)$ & $(0.022)$ \\
& $0.091^{* *}$ & 0.047 & $0.094^{* *}$ & 0.075 & $0.133^{* * *}$ \\
Respondent FEs & $(0.043)$ & $(0.052)$ & $(0.045)$ & $(0.046)$ & $(0.044)$ \\
State $\times$ Intake year FEs & $\mathrm{Y}$ & $\mathrm{Y}$ & $\mathrm{Y}$ & $\mathrm{Y}$ & $\mathrm{Y}$ \\
Age at entry FEs & $\mathrm{Y}$ & $\mathrm{Y}$ & $\mathrm{Y}$ & $\mathrm{Y}$ & $\mathrm{Y}$ \\
Controls & $\mathrm{Y}$ & $\mathrm{Y}$ & $\mathrm{Y}$ & $\mathrm{Y}$ & $\mathrm{Y}$ \\
Younger $\times$ Intake year & $\mathrm{Y}$ & $\mathrm{Y}$ & $\mathrm{Y}$ & $\mathrm{Y}$ & $\mathrm{Y}$ \\
Controls $\times$ Post reform cohort & $\mathrm{Y}$ & $\mathrm{Y}$ & $\mathrm{Y}$ & $\mathrm{Y}$ & $\mathrm{Y}$ \\
Sample & $\mathrm{Y}$ & $\mathrm{Y}$ & $\mathrm{Y}$ & $\mathrm{Y}$ & $\mathrm{Y}$ \\
Observations & 17,749 & 15,133 & 16,717 & 17,042 & 17,694 \\
\hline \hline
\end{tabular}

Unit of observation is the score for a given IAS officer in 2012-13 with at least 8 years of tenure. Relating cross-section of perceived effectiveness, probity, ability to withstand illegitimate political pressure, propoor orientedness and overall scores to the number of younger cohort members for cohorts entering before/after the pension reform. Younger is the number of IAS officers in the same cohort (i.e. the same allocated state and intake year) who are younger than the IAS officer. Post reform cohort is a dummy that is 1 if the IAS officer entered in the year of the pension reform 1998 or after. Respondent FEs are fixed effects for each survey respondent. State $\times$ Intake year FEs are fixed effects for the state-specific cohort the officer entered in. Age at entry FEs are dummies for each entry age. Individual controls are: female dummy, caste dummies (OBC, SC, ST), a dummy for coming from an urban area, having received an academic distinction, a STEM or Economics degree, having worked in education/research, private sector/SOEs, public sector, public AIS, standardized scores for the (UPSC) entry and training scores, as well as a dummy that is 1 if the officer improved the ranking in the training relative to the entry exam. Younger $\times$ Intake year is the (linear) interaction of the number of younger officers and the intake year. Controls $\times$ Post reform cohort interacts all individual background controls with the reform dummy. Standard errors are clustered at the individual-level. ${ }^{* * *} p<0.01,{ }^{* *} p<0.05,{ }^{*} p<0.1$. 
Figure 1: Seniority based progression: Average payscale and years of tenure

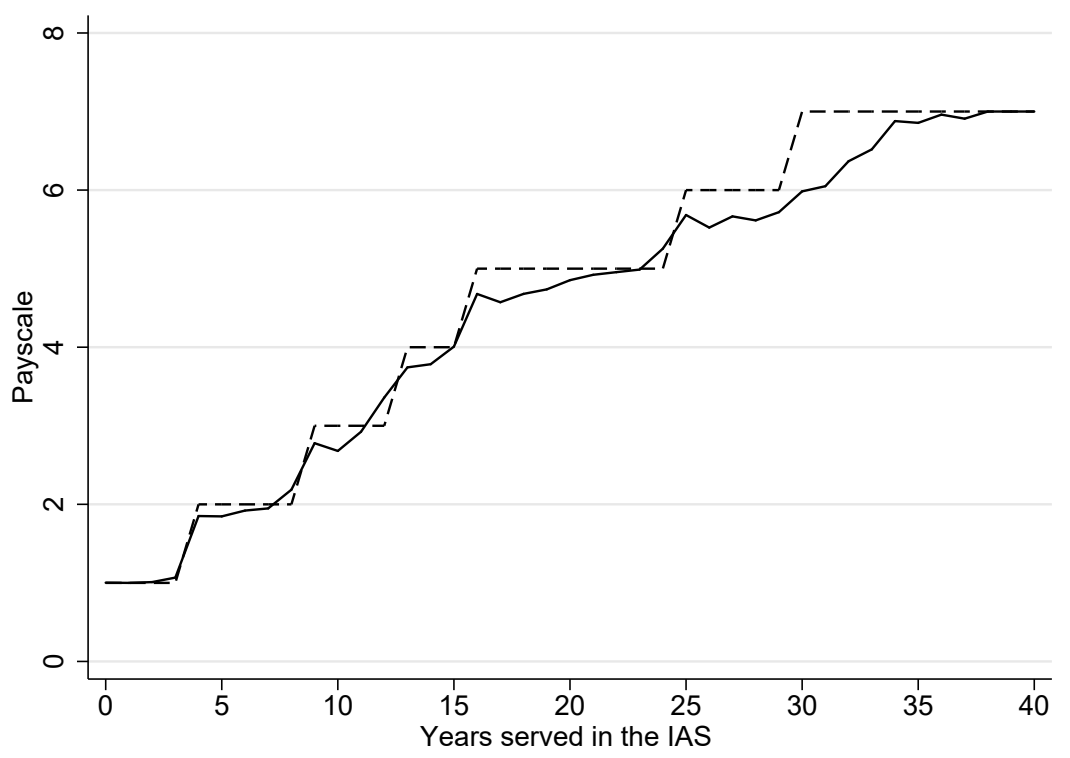

Average payscale of IAS officers as a function of the years served in the IAS (solid line) for the crosssection of all centrally recruited IAS officers active in 2012. The dashed line marks the payscale as predicted using the IAS promotion guidelines. 
Figure 2: Share of retired officers reaching senior payscales as a function of age at entry

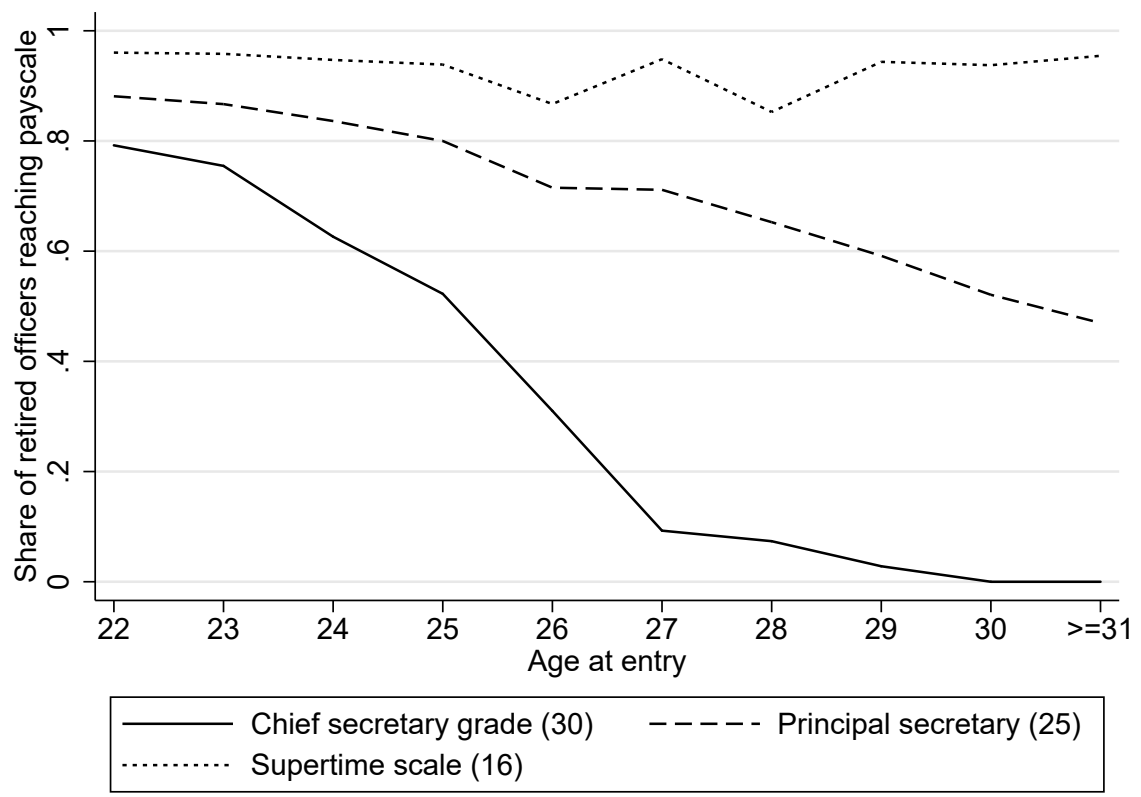

Share of retired officers in 2012 reaching senior payscales as a function of age at entry. Number in parentheses indicates the minimum number of years to qualify for promotion to the position. 
Figure 3: Effectiveness and age at entry (pre-reform)

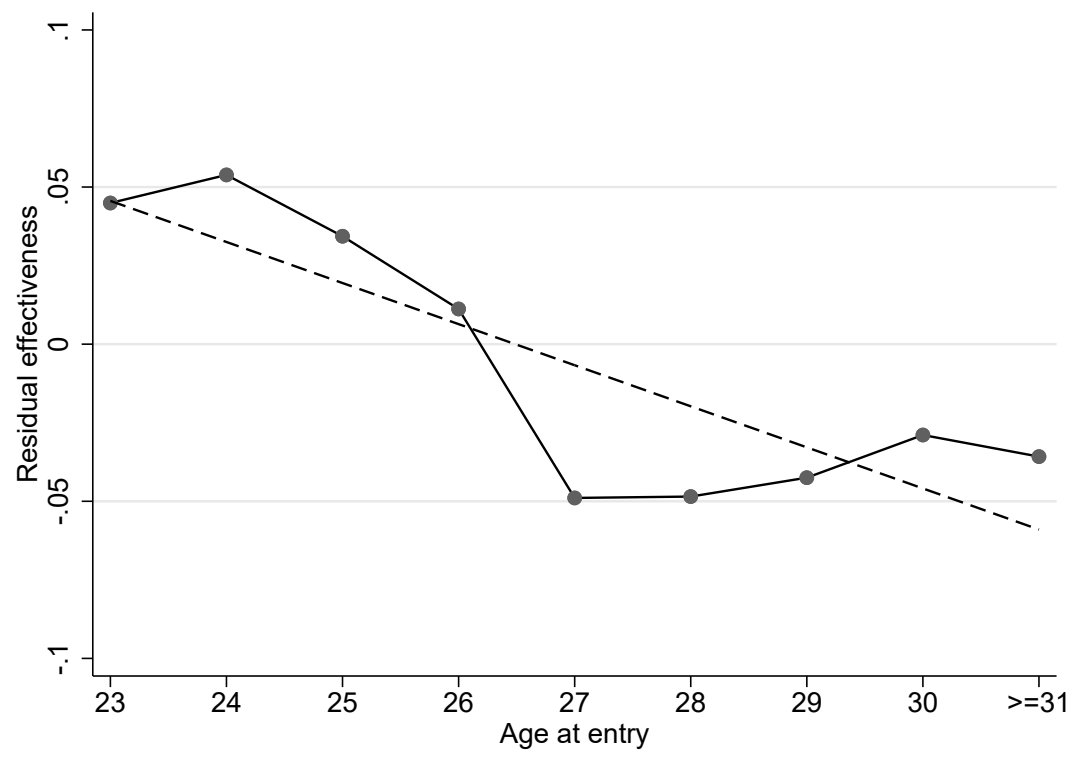

Relationship between effectiveness and age at entry after partialling out respondent fixed effects for sample of officers entering before the 1998 pension reform. 
Figure 4: Distribution of age at retirement pre/post-1998

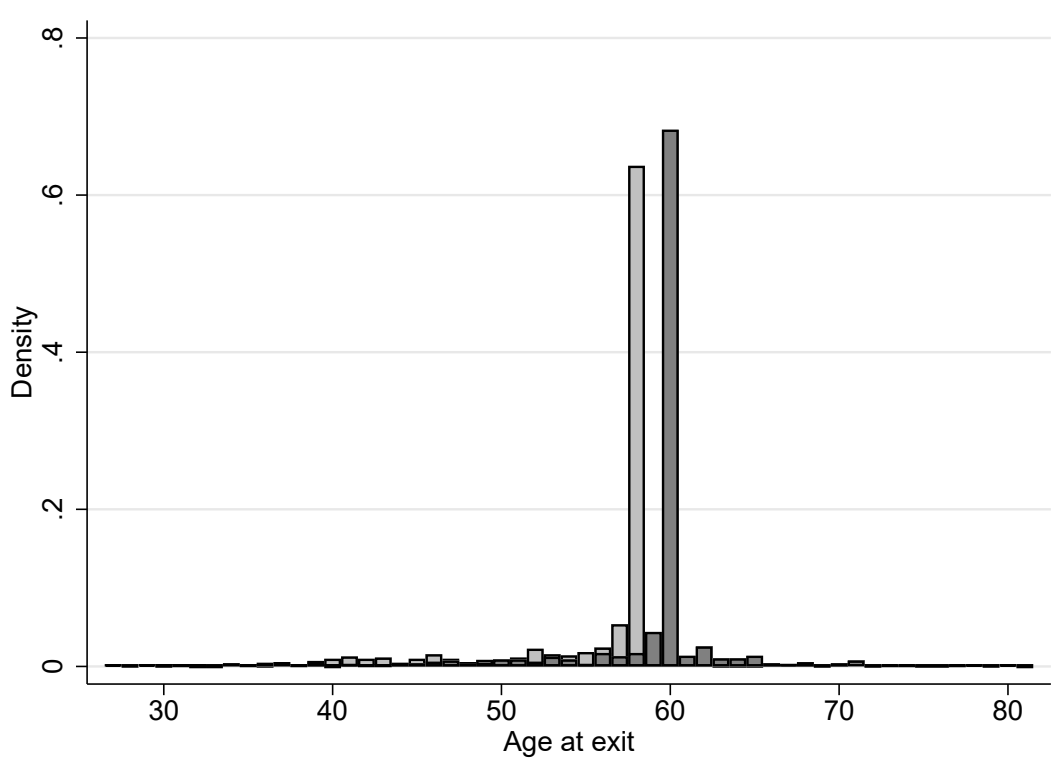

Distribution of age at exit from IAS among retired officers in 2012. Grey (black) bars denote retirement before (after) 1998. The retirement age was raised from 58 to 60 in 1998. 
Figure 5: Share of retired officers reaching top scale by age at entry, pre/post reform

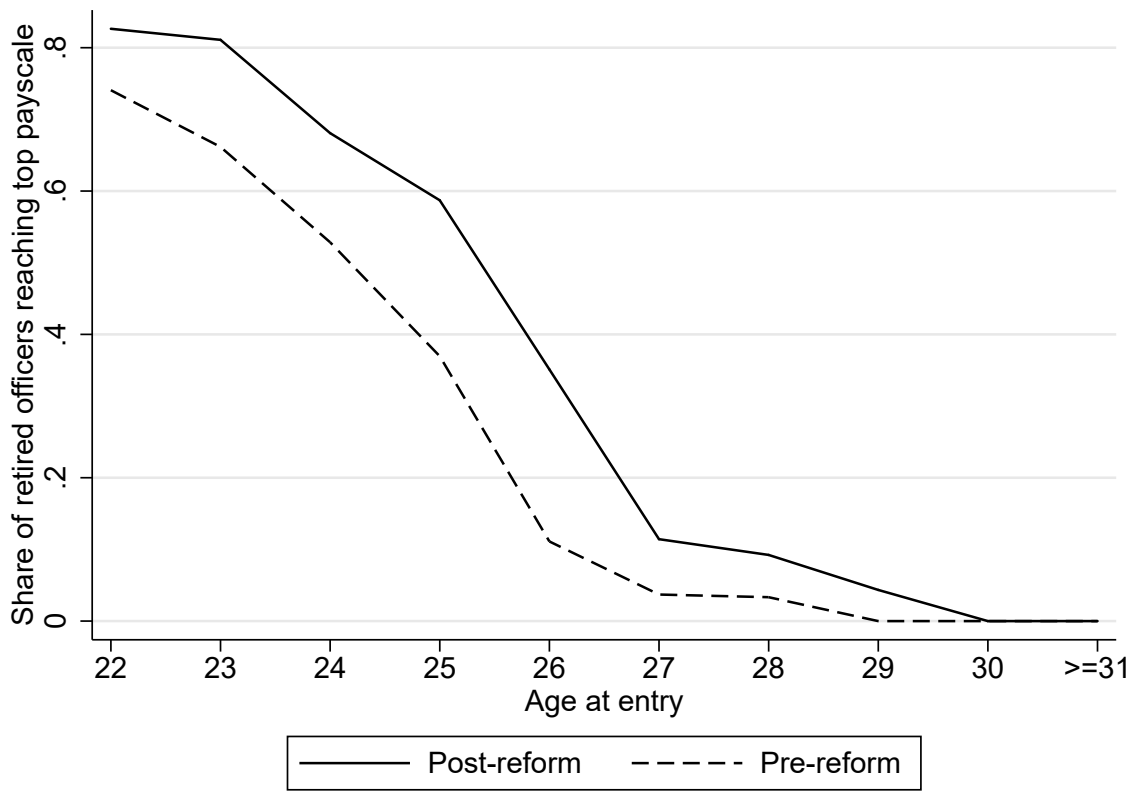

Share of retired officers by 2012 reaching the top payscale (30 years minimum tenure) as a function of age at entry, broken down by those retiring pre/post 1998 retirement reform. 
Figure 6: Years eligible for promotion to highest payscale, pre/post reform

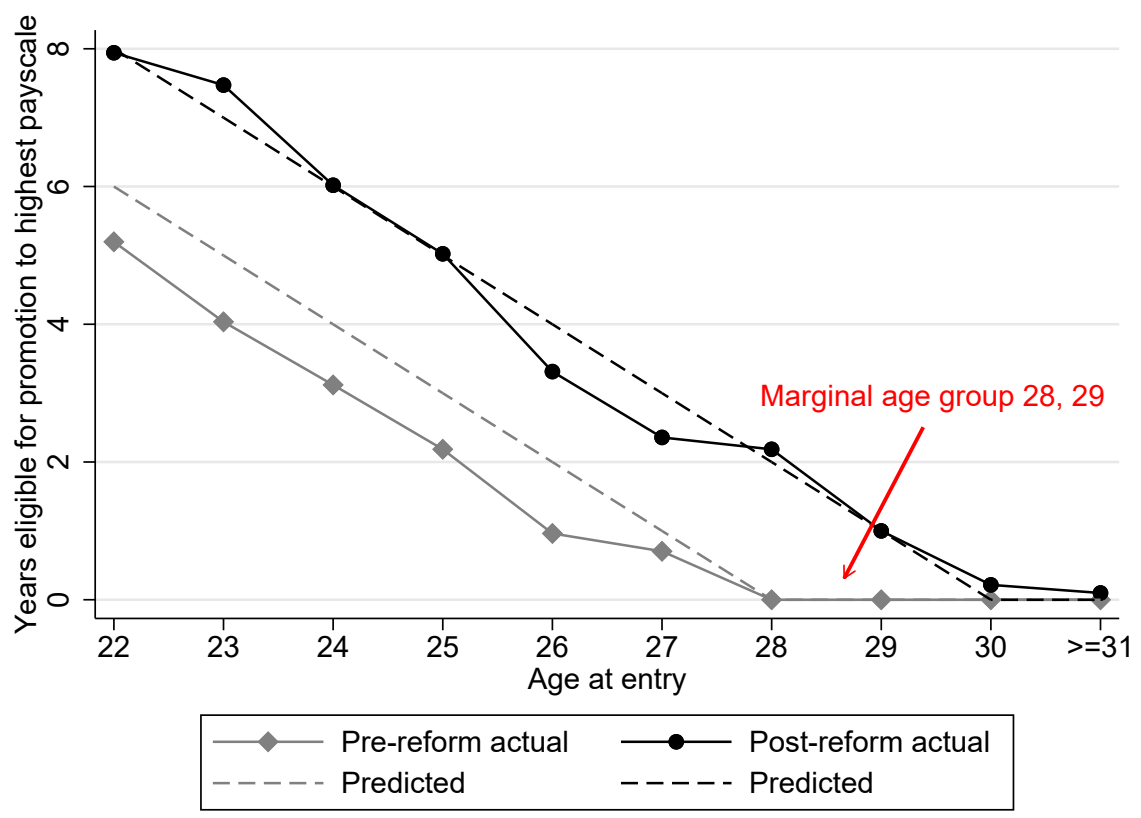

Years eligible for promotion to highest payscale (requiring at least 30 years of service). Dashed lines indicate the predicted number based on the pre/post reform retirement ages (58 pre-reform, 60 postreform). The solid lines mark the observed years. 
Figure 7: Effectiveness and pension reform 1998, by intake year

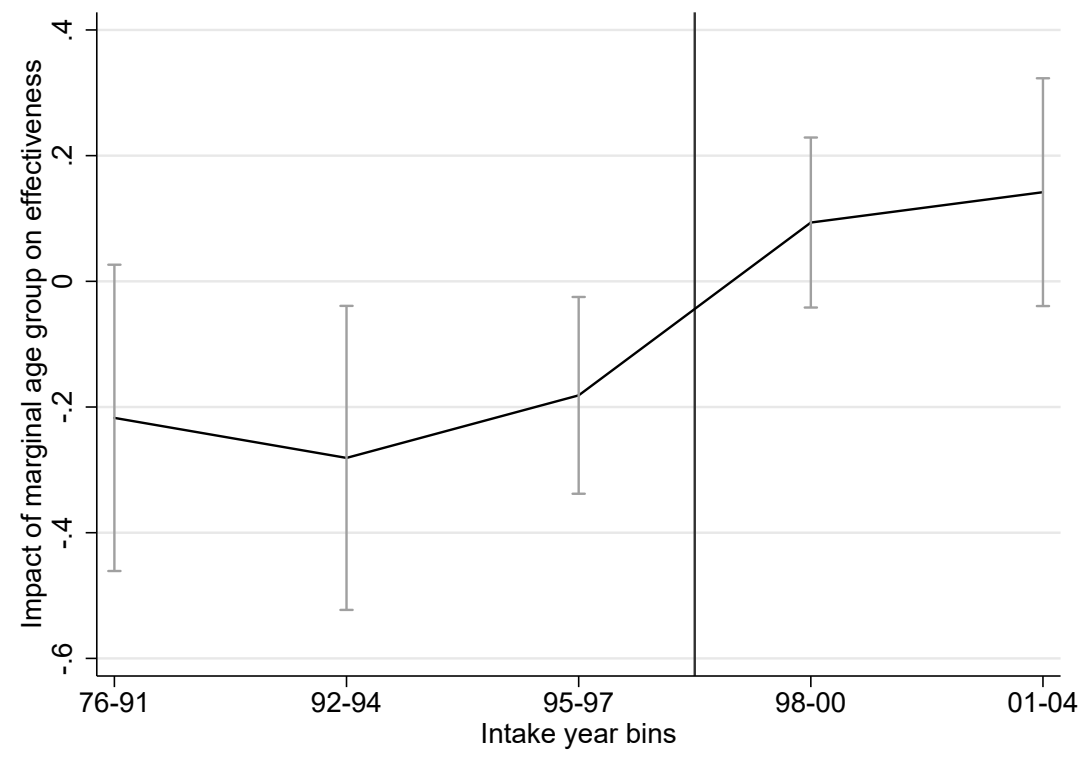

Summarizing the coefficients of a regression of the effectiveness score on a dummy for being in the marginal group (age at entry of $[28,29]$ ) interacted with intake year bins between 1976-2004. The regression also allows being in the old group (age at entry of at least 30) to vary by intake year, and includes all individual background controls (female dummy, caste dummies, dummy for urban background, having received an academic distinction, a STEM or Economics degree, having worked in education/research, private sector/SOEs, public sector, public AIS, standardized scores for entry and training scores, a dummy that is 1 if the officer improved the ranking in the training relative to the entry exam), respondent fixed effects and state cadre FEs, and dummies for being in the marginal/too old group interacted with intake year (centered around 1998, See Table 5, Column 1). The solid line marks the year of the pension reform. Standard errors used for computation of the $90 \%$ confidence intervals are clustered at the individual-level. 
Figure 8: Suspension and pension reform 1998

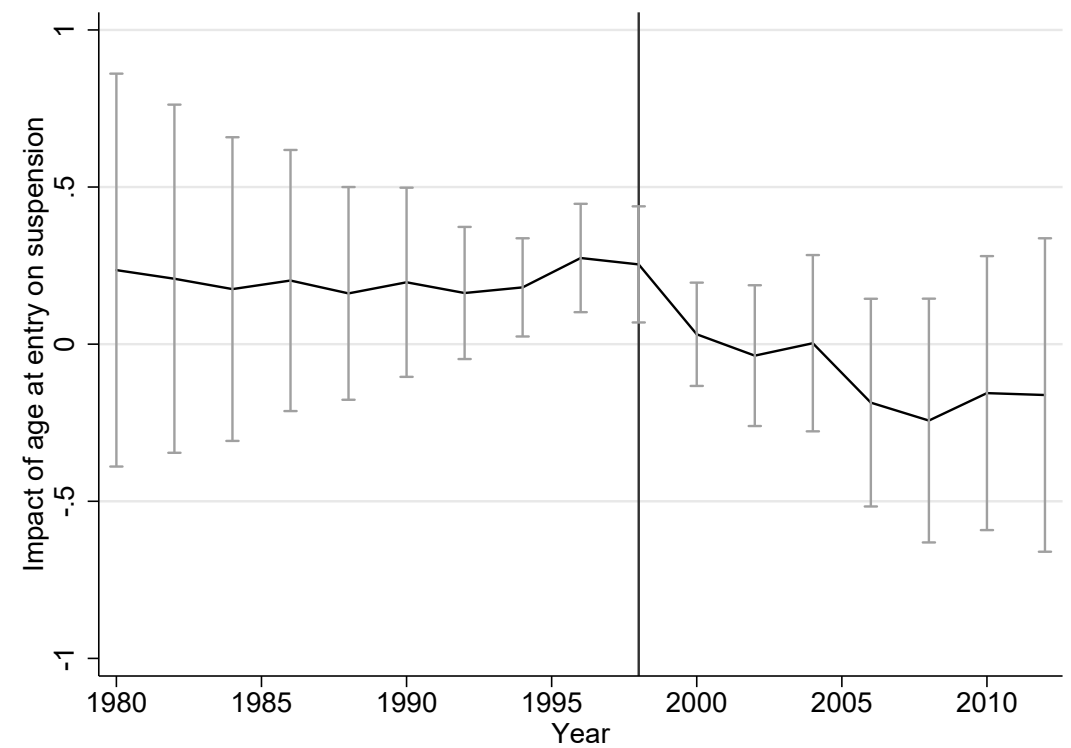

The impact of age at entry on suspensions by two-year bins. The regression includes year FEs, cadre FEs, experience/tenure FEs, and age at entry interacted by year (centered around 1998), see Table 6, Column 5. The coefficients are rescaled by 100 to improve readability. The solid line marks the year of the pension reform. Standard errors used for computation of the $90 \%$ confidence intervals are clustered at the individual-level. 